\title{
Reticulospinal Vasomotor Neurons of the Rat Rostral Ventrolateral Medulla: Relationship to Sympathetic Nerve Activity and the C1 Adrenergic Cell Group
}

\author{
Shaun F. Morrison, Teresa A. Milner, and Donald J. Reis \\ Division of Neurobiology, Department of Neurology, Cornell University Medical College, New York, New York 10021
}

Neurons projecting from the rostral ventrolateral medulla (RVL) to the spinal cord were antidromically identified in rats anesthetized with urethane, paralyzed, and ventilated. The sites of lowest antidromic threshold were concentrated in the intermediolateral nucleus (IML). Their axonal conduction velocities were distributed bimodally, with the mean of the rapidly conducting fibers ( $>1 \mathrm{~m} / \mathrm{sec}$ ) being $3.1 \pm 0.1 \mathrm{~m} / \mathrm{sec}$ $(n=105)$, and of the slower axons being $0.8 \pm 0.03 \mathrm{~m} / \mathrm{sec}$ $(n=25)$. Single-shock electrical stimulation of RVL elicited 2 bursts of excitation in splanchnic sympathetic nerve activity (SNA), which resulted from activation of 2 descending pathways with conduction velocities comparable to those of antidromically excited RVL-spinal neurons. The probability of discharge of RVL-spinal cells was synchronized both with the cardiac-related bursts in SNA with functional baroreceptor reflexes and with the free-running 2-6 Hz bursts in SNA following baroreceptor afferent denervation. On the average, their spontaneous discharges occurred $67 \pm 2 \mathrm{msec}(n=$ $31)$ prior to the peak of the spontaneous bursts in splanchnic SNA. This time corresponded to the latency to the peak of the early excitatory potential in splanchnic SNA following electrical stimulation of RVL. Baroreceptor reflex activation inhibited RVL-spinal neurons.

The recording sites of RVL-spinal vasomotor neurons were consistently located within $100 \mu \mathrm{m}$ of cell bodies (C1 neurons) immunoreactive for the adrenaline-synthesizing enzyme phenylethanolamine $\mathrm{N}$-methyltransferase (PNMT). UItrastructural analysis of the lateral funiculus of the cervical and thoracic spinal cord demonstrated PNMT immunoreactivity within myelinated (0.6-2.1 $\mu \mathrm{m}$ diameter) and unmyelinated (0.1-0.8 $\mu \mathrm{m}$ diameter) axons. Estimated conduction velocities of these fibers were comparable to the antidromic conduction velocities of the rapidly and slowly conducting populations of RVL-spinal vasomotor neurons.

We conclude that in rat, the discharge of RVL-spinal vasomotor neurons strongly influences SNA: the baroreceptormediated inhibition of these neurons is reflected in the cardiac locking of SNA, while, in the absence of baroreceptor input, the synchronous discharge of RVL-spinal neurons

\footnotetext{
Received May 19, 1987; revised Sept. 14, 1987; accepted Sept. 14, 1987

This work was supported by National Institutes of Health Grants HL 18974 and NS 22721. We wish to thank Drs. C. Abate, D. H. Park, and T. H. Joh for their generous supply of PNMT antibody.

Correspondence should be addressed to Dr. Shaun Morrison, Division of Neurobiology, Cornell University Medical College, 411 E. 69th Street, New York, NY 10021 .

Copyright $(1988$ Society for Neuroscience $0270-6474 / 88 / 041286-16 \$ 02.00 / 0$
}

maintains a free-running 2-6 $\mathrm{Hz}$ bursting pattern in SNA. RVL-spinal neurons are located within, and may be elements of, the $\mathrm{C}_{1}$ adrenergic cell group, and they provide a sympathoexcitatory drive to neurons in the IML over rapidly and slowly conducting pathways that correspond to myelinated and unmyelinated spinal axons containing PNMT.

It is now accepted that neurons in a zone topographically defined as the rostral ventrolateral medulla (RVL) play a critical role in governing the circulation. Such neurons provide the tonic excitation to sympathetic preganglionic neurons in the spinal intermediolateral nucleus (IML) necessary for the maintenance of resting sympathetic tone and arterial pressure (Guertzenstein and Silver, 1974; Dampney and Moon, 1980; Willette et al., 1983; Ross et al., 1984b; Granata et al, 1985). They function as the final common reticulospinal pathway mcdiating the circulatory responses to activation of baroreceptor (McAllen et al., 1982; Willette et al., 1984; Granata et al., 1985; Sun and Guyenet, 1985) and somatosympathetic (McAllen, 1985; Morrison et al., 1986) reflexes. Neurons of the RVL also serve as relays effecting the sympathetic responses to stimulation of other brain regions (Barman and Gebber, 1983; Hilton et al., 1983; Brown and Guyenet, 1985). Anatomically, RVL neurons project directly to the IML (Amendt et al., 1979; Ross et al., 1981, 1984a; Muira et al., 1983) and receive substantial innervation from neurons in regions of the nucleus tractus solitarii (NTS) comprising the terminal fields of baroreceptor and chemoreceptor afferents (Loewy and Burton, 1978; Ross et al., 1985). Electrophysiologically, neurons in the RVL have been identified that can be antidromically activated from the spinal cord in the rat (Brown and Guyenet, 1984), rabbit (Terui et al., 1986), and cat (Barman and Gebber, 1983, 1985; McAllen, 1986). The activity of such neurons was modulated by baroreceptor stimulation. In rat and rabbit, 2 populations of reticulospinal cardiovascular neurons were identified: one with rapidly conducting and the other with slowly conducting spinal axons.

The cytological identity of neurons in the RVL that function as sympathoexcitatory vasomotor neurons is uncertain. We have proposed (Ross et al., 1983, 1984b) that the sympathoexcitatory neurons in RVL correspond to adrenergic neurons of the $\mathrm{Cl}$ group (Hökfelt et al., 1974), identifiable in the RVL by immunocytochemical labeling of the adrenaline-synthesizing enzyme phenylethanolamine $N$-methyl transferase (PNMT) (Armstrong et al., 1982).

In support of the " $\mathrm{Cl}$ hypothesis" are the observations in rat that (1) adrenergic neurons in the rostral $\mathrm{Cl}$ group project to the spinal cord, where they terminate exclusively within the 
IML (Ross et al., 1981, 1983, 1984a), (2) the lowest-threshold sites in the RVL for electrically or chemically evoked pressor responses or wherein lesions abolish baroreceptor reflex responses and lower arterial pressure correspond exactly to the location of $\mathrm{C} 1$ neurons or their axonal trajectories (Ross et al., 1984b; Granata et al., 1985), and (3) the C1 area precisely overlies the chemosensitive zone of the ventral surface of the medulla, a region in which a variety of agents profoundly affect arterial pressure (Benarroch et al., 1986a).

Lacking, however, is direct electrophysiological evidence that the neurons exhibiting activity and response patterns indicative of a tonic sympathoexcitatory function are located within the $\mathrm{Cl}$ group. Indeed, in investigations in rat (Brown and Guyenet, 1984), cardiovascular neurons in RVL were believed to be localized to the nucleus paragigantocellularis lateralis (PGCL), a large region containing, in part, serotoninergic and substance $P$ neurons that project to the IML region of the spinal cord (Loewy and McKellar, 1981; Helke et al., 1982).

Therefore, in the present study, we combined electrophysiological methods with immunocytochemical localization of PNMT to ascertain whether the reticulospinal vasomotor neurons in the rat RVL correspond in their distribution to the $\mathrm{Cl}$ group, and whether both the rapidly and slowly conducting populations subserve a sympathoexcitatory function. We also examined the ultrastructure of the lateral funiculus of the spinal cord to determine whether the degree of myelination of PNMT. containing spinal axons would be appropriate for their function in the RVL-spinal sympathoexcitatory pathway. Preliminary communications of some of these data have been published (Morrison et al., 1986).

\section{Materials and Methods}

\section{General procedures}

Male Sprague-Dawley rats (350-450 gm) were anesthetized with intraperitoneal injections of urethane $(1.4 \mathrm{gm} / \mathrm{kg})$. The trachea, femoral veins, and femoral artery were cannulated for artificial ventilation, infusion of drugs, and measurement of arterial pressure, respectively. Rectal temperature was maintained at $37^{\circ} \mathrm{C}$ with a thermostatically controlled heating table. The animal was placed in a stereotaxic apparatus and spinal investigation unit (David Kopf Instruments), with the bite bar $11 \mathrm{~mm}$ below the interaural line and the spinal clamp on the T8 and T9 vertebral processes. An occipital craniotomy and T1-T3 laminectomy were performed. Exposed nervous tissue was covered with warm mineral oil. Following paralysis with gallamine triethiodide (initial dose, $6 \mathrm{mg} / \mathrm{kg}$; supplements, $2 \mathrm{mg} / \mathrm{kg} / \mathrm{hr}$ ), animals were artificially respired with $100 \%$ oxygen at a volume of $200-250 \mathrm{ml} / \mathrm{min}$. A pneumothorax reduced respiration pump-related movements of tissue near the rccording electrodes. For baroreceptor reflex activation, phenylephrine $(100$ $\mu \mathrm{g} / \mathrm{ml}$ saline) was infused intravenously to produce a rise in arterial pressure.

\section{Baroreceptor denervation}

Using a ventral approach, nerves containing baroreceptor afferents (Andrew, 1954; McDonald, 1983; Hofer, 1985) were isolated and transected. The cervical sympathetic and glossopharyngeal nerves were sectioned bilaterally, the latter just proximal to the entry of the carotid sinus nerve. The vagus nerves were sectioned between the nodose ganglion and the entry of the recurrent laryngeal nerve. The completeness of baroreceptor denervation was established by demonstration of (1) a disruption of the 1:1 relationship betwecn the bursts in splanchnic SNA and the cardiac cycle and (2) the elimination of the reflex inhibition of SNA during elevations of arterial pressure produced by infusion of phenylephrine.

\section{Neural recordings}

The spontaneous and evoked action potentials of RVL-spinal neurons were recorded extracellularly (AC-coupled, 300-3000 Hz) with glass micropipettes $(2-6 \mathrm{M} \Omega$ at $1000 \mathrm{~Hz}$ ) filled with $2 \mathrm{M} \mathrm{NaCl}$ saturated with fast green dye (Sigma). The indifferent electrode was attached to the skull. Recording sites were marked with electrophoretic dye deposits (15 $\mu \mathrm{A}$ of cathodal current for 20 min). Constancy of spike amplitude and contour were used to assess the unitary nature of the recordings. Two observations suggest that neuronal activity was recorded from the cell bodies rather than from fibers passing through the region. First, separation of the action potentials of the initial segment and the somatodendritic regions could often be distinguished as an inflection along the rising phase of the unit spike. Second, the cells tested $(n=12)$ were excited by L-glutamate (Sigma, 1 M, pH 8) iontophoretically applied from a multibarrel pipette. Ejection currents were less than $50 \mathrm{nA}$, with retaining currents of 10-30 nA applied between ejection periods. Current balancing was effected with $2 \mathrm{M} \mathrm{NaCl}$ in an additional pipette barrel.

Postganglionic SNA was recorded from the central cut end of the left splanchnic nerve dissected distal to the suprarenal (Baljet and Drukker, 1979; Celler and Schramm, 1981) or cardiac (Sapru et al., 1982) ganglion in the region between the diaphragm and the adrenal gland. Nerve activity was recorded with platinum hook electrodes in a monopolar configuration, amplified (Grass Model 7P3), and filtered between 1 and $50 \mathrm{~Hz}$. SNA and arterial pressure were continuously monitored on a polygraph (Grass). The electrocardiogram (ECG) was recorded with subcutaneous chest electrodes. A Schmidt-trigger circuit was used to derive standardized pulses coincident with the R-wave of the ECG.

\section{Electrical stimulation}

Sites in the RVL were stimulated with single pulses (30-50 $\mu \mathrm{A}$ cathodal, $1 \mathrm{msec}, 0.5 \mathrm{~Hz}$ ) applied through glass micropipettes containing a carbon filament, $7 \mu \mathrm{m}$ in diameter, with an exposed tip of $10-25 \mu \mathrm{m}$. The anode was clipped to neck muscle. The facial nerve was stimulated with single pulses $(2 \mathrm{~mA}, 0.2 \mathrm{msec}, 0.5 \mathrm{~Hz})$ delivered through a concentric bipolar electrode (Rhodes Medical, SNE 100) inserted into the nerve bundle as it traversed the platysma muscle. Monitoring the magnitude of the resulting antidromic evoked potential (onset approximately $1.4 \mathrm{msec}$ ) allowed localization of the caudal pole of the facial nucleus (Brown and Guyenet, 1985).

To antidromically identify RVL neurons with axons that terminated in or passed near the spinal sympathetic nucleus, monopolar stimulation with $1 \mathrm{msec}$ cathodal pulses was delivered to sites in the IML region of T1-T3 through tungsten microclectrodes ctched to a $50 \mu \mathrm{m}$ cxposed tip. Stimuli applied to this area always elicited a short onset latency excitatory potential in the splanchnic nerve (e.g., Fig. 7, trace 2). Three criteria were used to distinguish antidromic activation of RVL neurons from that elicited orthodromically by stimulation of spinal afferent pathways: (1) constant onset latency, (2) high following frequency, and (3) the collision test (Lipski, 1981; Morrison and Gebber, 1984). These tests were performed using stimulus intensities at least $100 \mu \mathrm{A}$ greater than threshold. During the tests, pulses coincident with the unit discharges were obtained from a window discriminator and used to trigger an IBM-AT computer that delivered the desired stimulus configuration at a variable delay. These stimulation pulses were amplified and passed through a constant-current unit (Neurolog, NL-800).

\section{Data analysis}

Unit spikes were recorded on analog tape (HP 3968A) along with SNA, arterial pressure, and TTL pulses derived from either the R-wave of the ECG or stimuli delivered to the spinal cord or to the RVL. Data were analyzed with an IBM-AT computer using a Data Translation $\mathrm{A} / \mathrm{D}$ board at a $1 \mathrm{kHz}$ sampling rate for each analog signal. Programs were developed with Macmillan ASYST software to perform the following analyses: poststimulus averaging, post-R-wave analysis, and spiketriggered averaging. The applications of these averaging techniques have been previously described (Barman and Gebber, 1983; Morrison and Gebber, 1984, 1985).

\section{Immunocytochemical labeling for PNMT}

Recording sites in $R V L$. To determine the proximity of the recording sites of RVL-spinal neurons to the positions of $\mathrm{Cl}$ neurons, immunocytochemical labeling of PNMT-containing neurons was carried out on histologic sections of the medulla containing the fast green dye deposited from the tip of the recording microelectrode. Animals were perfused transcardially with $25 \mathrm{ml}$ of heparinized saline, followed by $500 \mathrm{ml}$ of $4 \%$ paraformaldehyde in $0.1 \mathrm{M}$ phosphate buffer (pH 7.4). 
Frozen microtome sections $(30 \mu \mathrm{m})$ were cut through the RVL and placed in $0.1 \mathrm{M}$ phosphate buffer. The polyclonal antiserum was produced in rabbits against PNMT that had been purified from bovine adrenal medulla and tested for immunological specificity, as previously described (Joh and Goldstein, 1973; Joh and Ross, 1983). The antiserum was localized in the tissue by a modification (Pickel, 1981) of the peroxidase-antiperoxidase (PAP) method of Sternberger (1979). Briefly, sections were sequentially incubated in (1) a 1:3000 dilution of the PNMT antiserum containing $0.25 \%$ Triton $\mathrm{X}-100$ for $12-18 \mathrm{hr}$, (2) a 1:50 dilution of goat anti-rabbit immunoglobulin (IgG) for $1 \mathrm{hr}$, and (3) a 1:100 dilution of a rabbit PAP complex for $1 \mathrm{hr}$. The diluents and the washes separating each of the incubations were prepared with $1 \%$ goat serum in $0.1 \mathrm{~m}$ Tris-saline. Incubations were done at room temperature with continuous agitation. The PAP reaction product was demonstrated by incubation with 3,3'-diaminobenzidine (DAB) and hydrogen peroxide. Sections were then mounted on gelatin-coated glass slides, dehydrated, cleared in xylene, and the coverslips were mounted with Histoclad. Sections containing the dyc deposit marking the unit rccording site were photographed and the distance to the nearest PNMTcontaining cell body was measured.

Electron microscopy of spinal axons. Electron-microscopic examination of spinal axons immunocytochemically labeled for PNMT allowed us to describe the diameters and myelination of these fibers. Following Nembutal $(50 \mathrm{mg} / \mathrm{kg}$, i.p.) anesthesia, male Sprague-Dawley rats $(250-300 \mathrm{gm})$ were perfused transcardially with $10 \mathrm{ml}$ of heparinized saline, followed by $75 \mathrm{ml}$ of $3.75 \%$ acrolein and $2 \%$ paraformaldehyde in $0.1 \mathrm{M}$ phosphate buffer (pH 7.4), followed by $200 \mathrm{ml}$ of $2 \%$ paraformaldehyde in $0.1 \mathrm{M}$ phosphate buffer. Coronal Vibratome sections $30-40 \mu \mathrm{m}$ thick were cut from blocks of the midcervical and the upper thoracic segments of the spinal cord. Following collection in 0.1 M. phosphate buffer, sections were placed in $1 \%$ sodium borohydride in $0.1 \mathrm{~m}$ phosphate buffer for $30 \mathrm{~min}$ (Schachner et al., 1977) to improve the immunocytochemical labeling (Milner et al., 1987). Sections were then rinsed in $0.1 \mathrm{M}$ phosphate buffer until the gaseous bubbles disappeared and then transferred to $0.1 \mathrm{M}$ Tris-saline ( $\mathrm{pH} \mathrm{7.6)}$. Immunocytochemical labeling for PNMT was carried out as described above for light microscopy, except that the PNMT antiserum incubation solution did not contain Triton X-100.

The labeled sections were postfixed for $2 \mathrm{hr}$ in $2 \%$ osmium tetroxide, washed in phosphate buffer, dehydrated through a graded series of ethanols, and flat-embedded in Epon 812 between 2 plastic coverslips. The lateral funiculus region containing PNMT-immunoreactive fibers was selected from these flat-embedded sections using a light microscope. Selected spinal sections were then placed in Beem capsules and ultrathin sections $(500 \AA)$ were cut from the surface of the plastic-embedded tissue. These were collected on grids, counterstained with $5 \%$ uranyl acetate for $20 \mathrm{~min}$ and Reynolds lead citrate for $5 \mathrm{~min}$ (Reynolds, 1963), and examined with a Philips 201 electron microscope. Labeled axon profiles were photographed and their areas determined from these micrographs using an image analysis system (Eyecom II and PDP 11-45). Myelin laminae were included in the area determinations. The axonal diameter was calculated as the diameter of a circle of equivalent area.

\section{Results}

Antidromic activation of $R V L-$ spinal neurons

Area explored. The RVL was systematically explored for neurons that were antidromically activated by electrical stimulation of the IML of the ipsilateral thoracic spinal cord. The area surveyed was confined to a region between 2.2 and $2.8 \mathrm{~mm}$ anterior, 1.7 and $2.1 \mathrm{~mm}$ lateral, and 1.8 and $2.6 \mathrm{~mm}$ ventral to the calamus scriptorius. Anatomically, this area extends about $500 \mu \mathrm{m}$ caudal to the facial nucleus, between the retrofacial nucleus and the ventral surface of the medulla. It is bordered medially by the nucleus gigantocellularis pars ventralis and the inferior olive and laterally by the spinal trigeminal nucleus. This region contains a large number of PNMT-immunoreactive neurons and corresponds to the rostral pole of the $\mathrm{C} 1$ cell group (Ruggiero et al., 1985).

In 54 rats, we recorded from $130 \mathrm{RVL}$ neurons that were excited at a constant latency by IML stimulation. These responses were elicited antidromically since (1) each neuron was activated with a constant onset latency (Fig. 1 $A$, trace 1), (2) they followed paired spinal stimuli with intershock intervals of less than 4 msec (i.e., had following frequencies greater than $250 \mathrm{~Hz}$ ), and (3) the responses of those neurons that were spontaneously active satisfied the requirements of the time-controlled collision test for antidromic activation (Lipski, 1981; Morrison and Gebber, 1984). An example of the collision test is seen in Figure 1, $A, B$. In this casc, IML stimulation produced a unit spike with an onset latency of $17.5 \mathrm{msec}$, but only when delivered at intervals greater than $19.0 \mathrm{msec}$ (critical delay) after a spontaneous spike (Fig. $1 A$ ). Paired spinal stimuli separated by intervals greater than $2.5 \mathrm{msec}$ always produced 2 responses in this RVL neuron, indicating the refractory period of the most refractory portion of membrane between the stimulation and recording sites. To obtain a more accurate measure of the refractoriness of the axonal membrane at the stimulation site, paired spinal stimuli were applied $10.0 \mathrm{msec}$ following a spontaneous spike (i.e., at less than the critical delay). Due to collision of the first of the paired responses with the spontaneous spike, only the response to the second shock was recorded (Fig. $1 B$, trace 1). The minimum intershock interval at which the second shock still elicited a unit spike was $1.5 \mathrm{msec}$, which was taken as a measure of the axonal refractory period (Swadlow, 1982). The critical delay was equal to the sum of the onset latency and the axonal refractory period, satisfying the requirements of the collision test.

All RVL neurons that responded antidromically to IML stimulation were localized to a small region (Fig. 2) ventral to a cluster of neurons in the retrofacial nucleus with respiratoryrelated discharge patterns. In the rostrocaudal plane, they were recorded only within a $500 \mu \mathrm{m}$ region immediately posterior to the caudal pole of the facial nucleus, as judged by the disappearance of the antidromic field potential elicited by facial nerve stimulation (Brown and Guyenet, 1985). Of the 130 RVL-spinal units studied, $66(51 \%)$ were spontaneously active. As a group, these neurons were recorded at mean arterial pressures between 75 and $110 \mathrm{mmHg}$ and fired with a mean discharge frequency of $9 \pm 1$ spikes/sec. The discharge patterns of these cells were often quite regular (see Fig. $3 A$ ), particularly those with higher firing rates.

Relationship of the antidromic threshold to the position of the stimulating electrode. In each experiment, the spinal stimulating electrode was initially positioned approximately $0.7 \mathrm{~mm}$ below the dorsal root entry zone in the second thoracic (T2) segment. While monitoring the evoked response in the splanchnic sympathetic nerve, the electrode position was adjusted to produce a short onset latency increase in SN $\Lambda$ with the lowest stimulus current $(8-30 \mu \mathrm{A})$. At these sites, the minimum current required to antidromically excite RVL neurons ranged from 4 to $800 \mu \mathrm{A}$ (mean, $240 \pm 36 \mu \mathrm{A} ; n=38$ ). Such a wide range of thresholds likely resulted from the fact that we stimulated only one site along the length of the intermediolateral cell column. In this regard, antidromic activation of RVL neurons could have arisen from stimulation of axonal processes terminating in the IML at varying distances rostral or caudal to the stimulating electrode or from stimulation of axons of RVL neurons coursing through the lateral funiculus (Ross et al., 1984a).

To obtain more specific information on the possible termination sites of RVL-spinal neurons, we identified spinal sites from which $11 \mathrm{RVL}$ neurons were antidromically driven with the lowest stimulus currents. After locating a rostrocaudal position at which the RVL neuron could be activated with a thresh- 

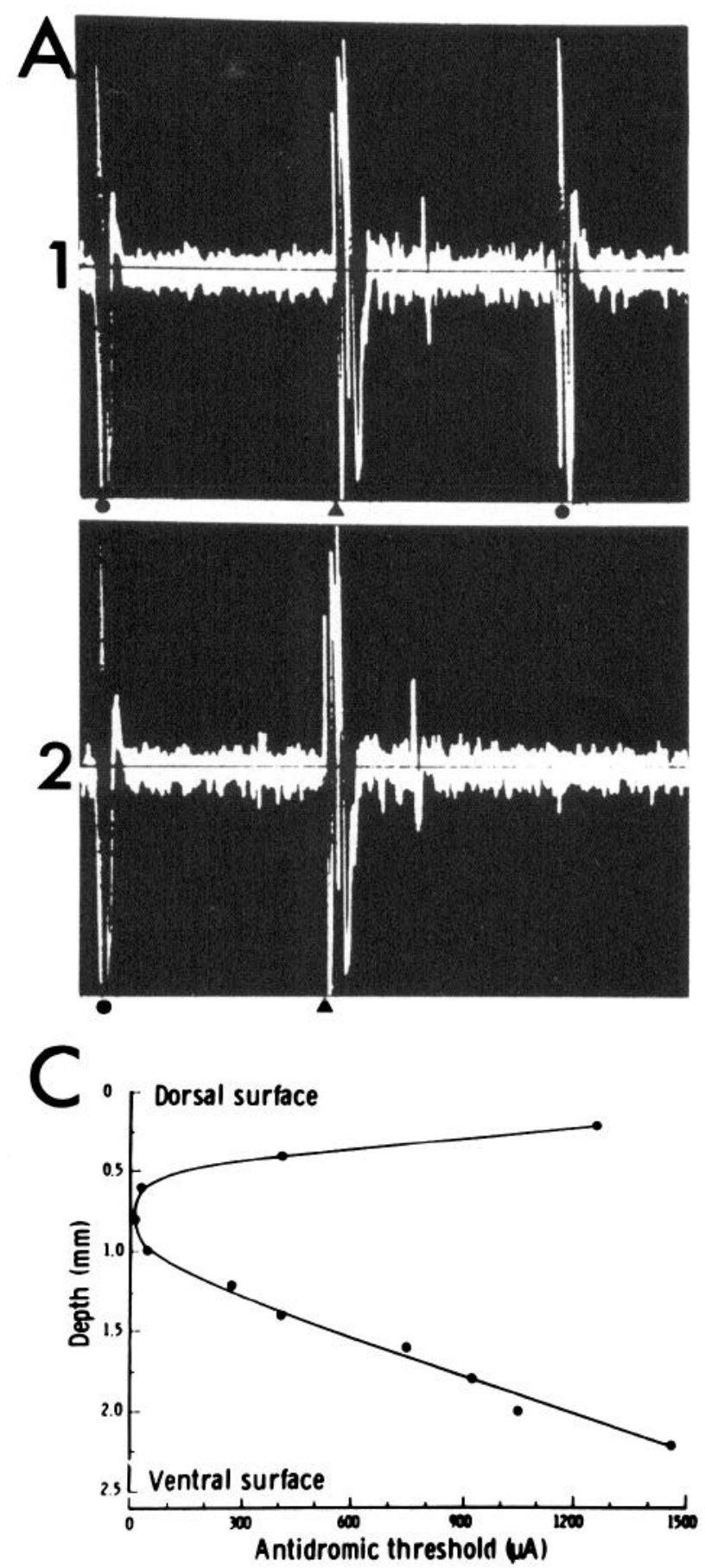
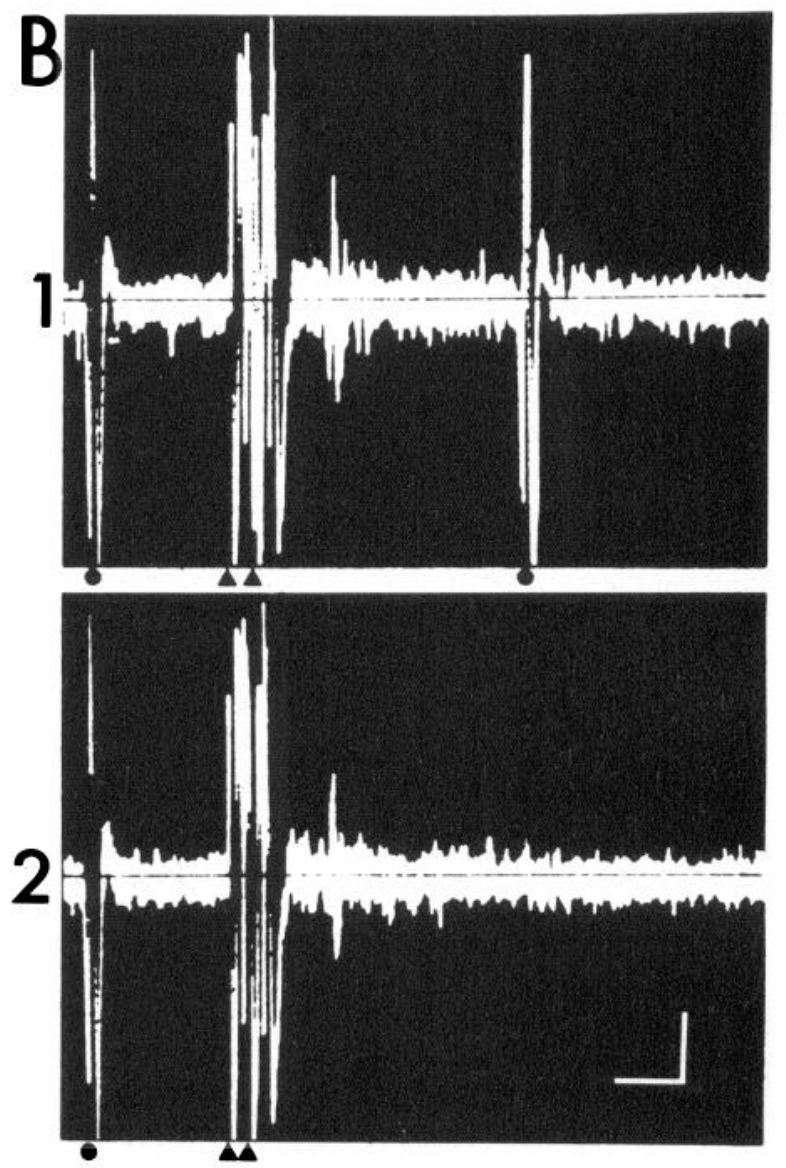

D

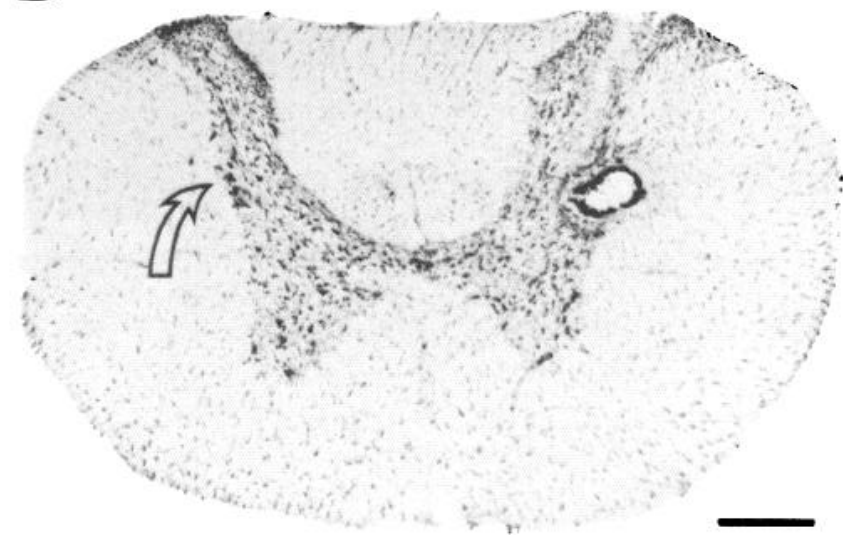

Figure 1. Responses of RVL neurons to spinal stimuli satisfied the time-controlled collision test for antidromic activation. Each panel contains 5 superimposed traces; filled circles below each panel indicate spontaneous or evoked action potentials, filled triangles indicate spinal stimulus artifacts. $A, 1$, At $19.0 \mathrm{msec}$ (or longer) following a spontaneous unit spike, spinal stimuli evoked a constant-latency unit response (onset, 17.5 $\mathrm{msec}$ ). 2, At $18.0 \mathrm{msec}$ following a spontaneous spike, no response was recorded because of collision. $B, 1$, When paired spinal stimuli $1.5 \mathrm{msec}$ (or longer) apart are delivered $10 \mathrm{msec}$ following a spontaneous spike, only the unit response to the second shock is recorded because of collision of the first with the spontaneous spike. 2, No response is recorded when the intershock interval is $1.3 \mathrm{msec}$ (or less). Vertical calibration ( $A$, $B$ ), $100 \mu \mathrm{V}$; horizontal calibration, $5 \mathrm{msec}$. $C$, Depth-threshold relationship showing the threshold stimulation intensity for the antidromic responses of a different RVL-spinal neuron activated from sites separated by $200 \mu \mathrm{m}$ in a ventral-to-dorsal track through the dorsal root entry zone of the second thoracic spinal segment. The onset latency of the response was $9.4 \mathrm{msec}$ at each site. $D$, Lesion marking the site of lowest threshold for the antidromic activation of this RVL neuron. Arrow indicates intermediolateral nucleus on contralateral side. Calibration bar, $0.5 \mathrm{~mm}$.

old of less than $200 \mu \mathrm{A}$, the stimulating electrode was lowered in $200 \mu \mathrm{m}$ steps along the dorsoventral axis. At each site, the threshold current required for antidromic excitation of the unit was established (Fig. 1C) (Morrison and Gebber, 1985). The lowest-threshold sites were consistently localized within or just lateral to the IML (Fig. 1D). In combination with the absence of low-threshold sites in either the dorsal or ventral horns, this finding provides good evidence that the axons of RVL-spinal 


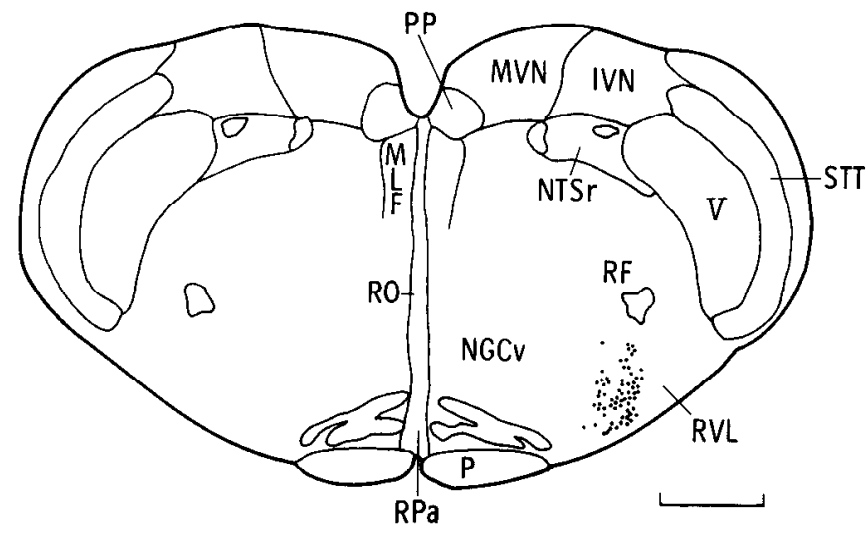

Figure 2. Recording sites (dots) of 66 spontaneously active RVL-spinal vasomotor neurons plotted on a coronal section through the rat medulla approximately $2.5 \mathrm{~mm}$ rostral to the calamus scriptorius. $I V N$, inferior vestibular nucleus; $M L F$, medial longitudinal fasciculus; $M V N$, medial vestibular nucleus; $N G C v$, nucleus reticularis gigantocellularis pars ventralis; NTSr, nucleus of the tractus solitarius pars rostralis; $P$, corticospinal tract; $P P$, nucleus prepositus; $R F$, retrofacial nucleus; $R O$, raphe obscurus; $R P a$, raphe pallidus; $R V L$, nucleus reticularis rostroventrolateralis; $S T T$, spinal trigeminal tract; $V$, spinal trigeminal nucleus.

neurons terminate near or pass in the vicinity of sympathetic preganglionic neurons in the IML.

\section{Spontaneous activity of $R V L-$ spinal neurons}

Relationship to rhythmic discharge in sympathetic nerves. To establish whether the activity of RVL-spinal neurons plays a significant role in determining the spontaneous (tonic) discharge of sympathetic nerves, we analyzed the relationship between the spontaneous firing of RVL neurons and the rhythmic component of SNA recorded from the splanchnic nerve. Figure $3 A$ illustrates a typical simultaneous recording of the discharge of an RVL-spinal neuron (lower trace), spontaneous sympathetic nerve firing (middle trace), and the arterial pressure (upper trace) in a rat with intact baroreceptor afferent nerves. The pattern of spontaneous splanchnic SNA consisted of rhythmic excitatory bursts associated with each cardiac cycle. These were displayed as slow waves, with the amplifier bandpass at $1-50 \mathrm{~Hz}$. The frequency of sympathetic slow waves ranged between 6 and 8 $\mathrm{Hz}$ at heart rates of 380-480 bpm. The peak of each slow wave occurred during early diastole. RVL-spinal neurons discharged in most, but not all, cardiac cycles. It is important that their action potentials were followed by peaks in sympathetic slow waves, suggesting that the discharges of RVL-spinal neurons could lead to the bursts of excitation in the sympathetic nerve.

The cross-correlational technique of spike-triggered averaging (Gootman et al., 1975; Gebber and Barman, 1981; Morrison and Gebber, 1984) provided a quantitative method for establishing the consistency and the temporal aspects of the relationship between the firing of RVL neurons and the rhythmic bursts in SN $\Lambda$. The example in Figure $3 B$, trace 1, shows the average of splanchnic SNA during the $250 \mathrm{msec}$ period following 1150 spontaneous spikes (time 0) of the RVL-spinal neuron depicted in Figure 3A. Note that the average waveform is in rhythm with the period of the cardiac cycle $(128 \mathrm{msec}$; upper trace, Fig. $3 A$ ), indicating that, on the average, the RVL unit discharges were locked to the cardiac-related component of SNA and occurred prior to the peak activation of splanchnic nerve fibers.
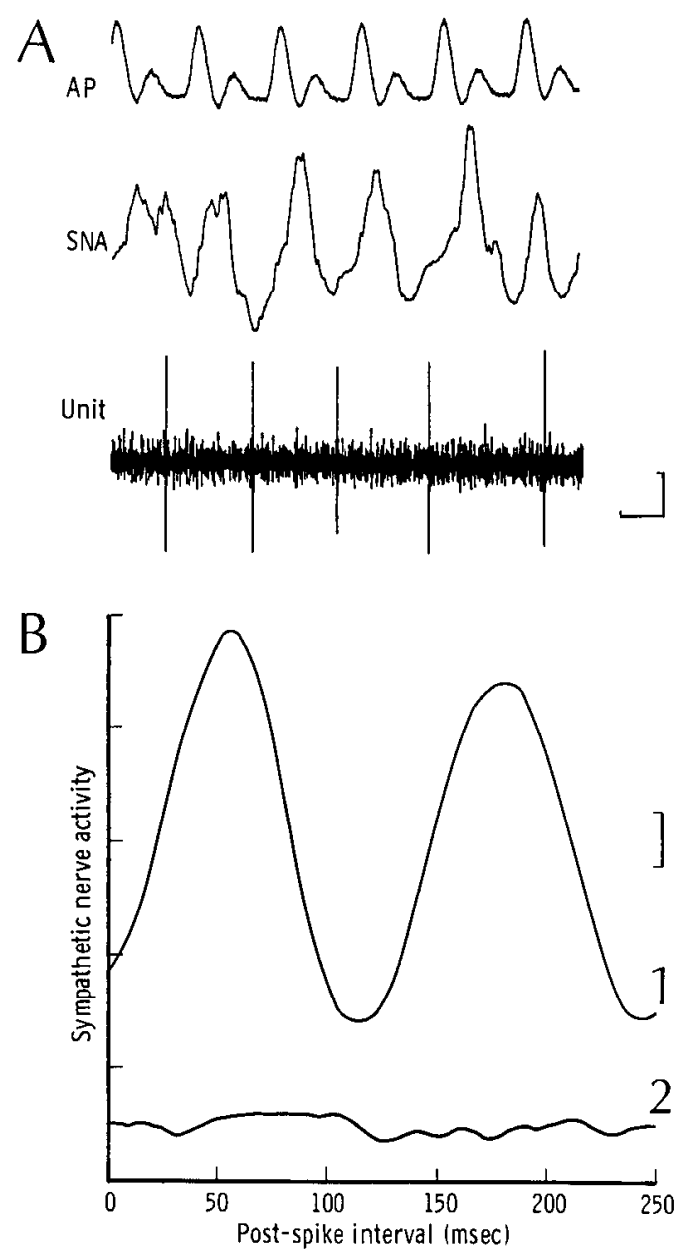

Figure 3. A, Digitized record of arterial pressure $(A P)$, spontaneous splanchnic sympathetic nerve activity ( $S N A$ ), and spontaneous RVLspinal unit discharge. AP was 135/100; vertical calibration, $70 \mu \mathrm{V}$ for SNA and $80 \mu \mathrm{V}$ for unit spikes; horizontal calibration, $70 \mathrm{msec} . B, 1$, Average of spontaneous SNA triggered (time 0 ) by spontaneous spikes of RVL neuron in $A$. 2, Average of same SNA recording triggered by random pulse train of same frequency as RVL neuron. 1 , 2, Sweeps 1150 ; bin width, $1 \mathrm{msec}$; vertical calibration, $10 \mu \mathrm{V}$.

In contrast, when a random pulse train of the same average frequency as that of the RVL neuron was used to trigger each $250 \mathrm{msec}$ sweep of SNA, the resulting average (Fig. $3 B$, trace 2) was flat, indicating the absence of a consistent temporal relationship between the pulse train and the bursts in SNA.

These results suggest a predictable coupling between the spontaneous activity of RVL-spinal neurons and the cardiac-related bursts in SNA. For 31 RVL-spinal neurons, the mean lag between the occurrence of RVL unit spikes and the peak of the succeeding slow wave in SNA was $67 \pm 2 \mathrm{msec}$.

Relationship to the cardiac cycle. We examined the relationship of RVL neuronal activity and SNA to the cardiac cycle using post-R-wave analysis. To detect events or trends occurring at a regular time with respect to the cardiac cycle, the R-wave of the ECG is used to trigger an average of the physiological variable of interest. The middle trace in Figure 4 depicts the $\mathrm{R}$-wave-triggered average of the spontaneous SNA, and in the lower trace the post-R-wave-interval histogram of the activity of an RVL neuron (same unit as in Fig. 3). The unit spikes recorded during 2240 cardiac cycles were displayed as the num- 

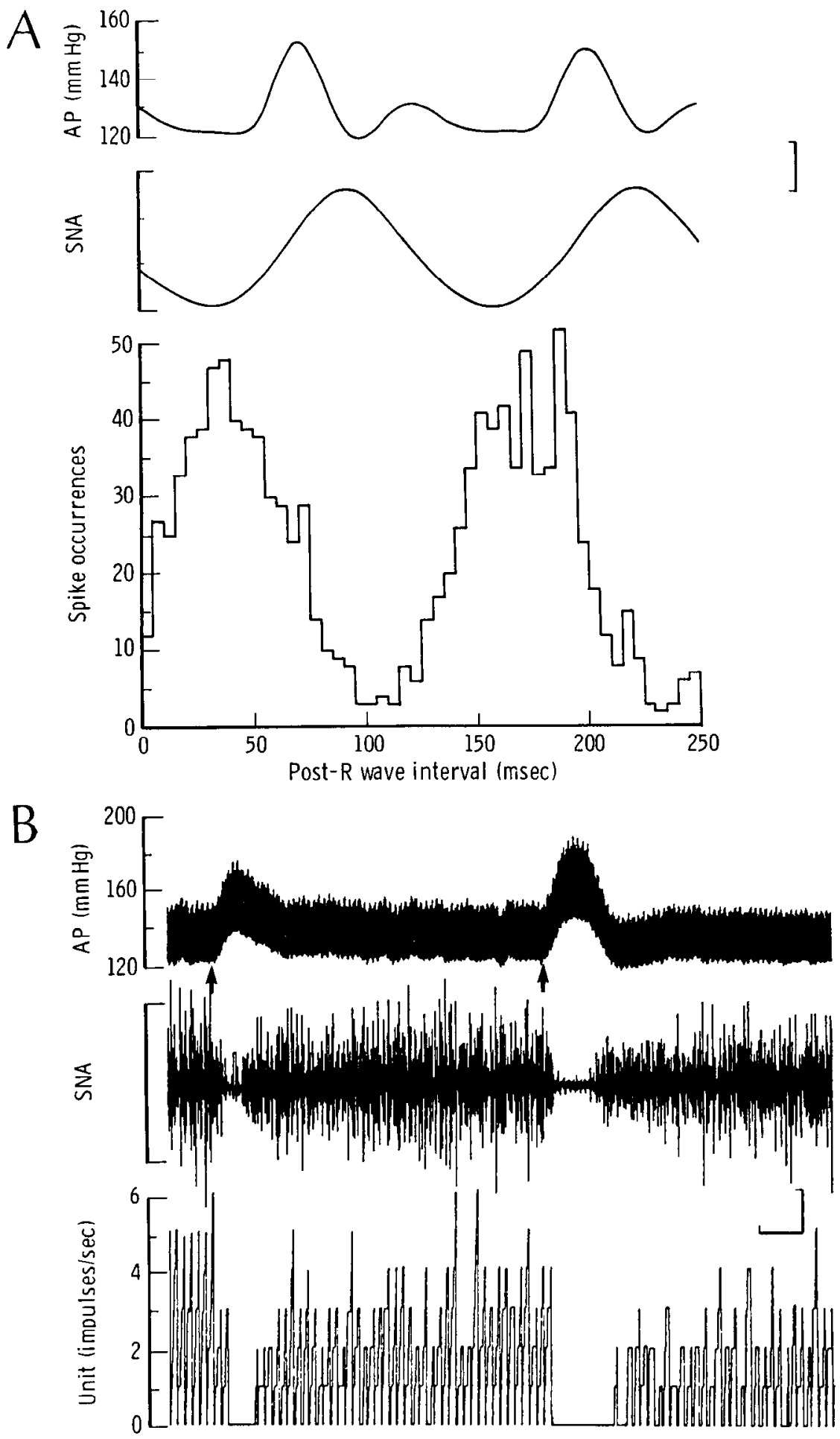

Figure 4. A, Post-R-wave averages of $\mathrm{AP}$ and SNA and histogram of RVL unit (same as Fig. 3) discharges. Sweeps 1120 ; bin width, 1 msec for averages, $5 \mathrm{msec}$ for histogram; vertical calibration for SNA, $50 \mu \mathrm{V}$. $B$, Effect of phenylephrine-induced increases in AP (arrows) on spontaneous SNA and discharge frequency of RVL-spinal neuron. Vertical calibration for SNA, $100 \mu \mathrm{V}$; horizontal calibration, $6 \mathrm{sec}$.

ber of action potentials occurring in each $5 \mathrm{msec}$ period following the R-wave of the ECG. These are displayed over 2 cardiac cycles to illustrate the consistency of the prominent peak in the discharge probability of this neuron in each cardiac cycle. The demonstration that the discharge probability of this cell was modulated in synchrony with the arterial pulse wave was typical of the activity of the $30 \mathrm{RVL}$-spinal neurons analyzed in this manner.

These results demonstrate first that in rat, as in cat (Koizumi et al., 1971), the spontancous discharge of the splanchnic sympathetic nerve is synchronized with the cardiac cycle. Second, RVL-spinal neurons exhibit a nonuniform probability of discharge over the cardiac cycle, with the peak of excitation occurring in late diastole, approximately $60 \mathrm{msec}$ in advance of the peak in SNA. Note, however, that these neurons do not fire predictably at a precise time in the cardiac cycle (Fig. 4), but that, rather, their discharges fluctuate over a range of many milliseconds with respect to the $\mathrm{R}$-wave. This suggests that the 


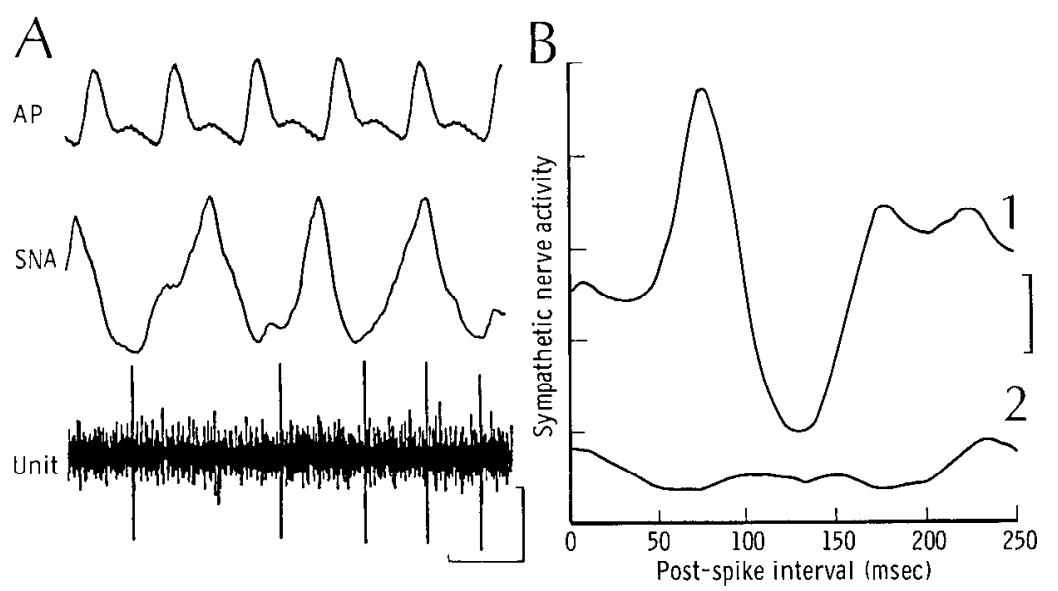

Figure 5. Data recorded from baroreceptor denervated rat. $A$, Digitized record of AP, spontaneous SNA, and discharges of RVL-spinal neuron. Note disruption of $1: 1$ synchrony between AP waves and bursts in SNA. AP was $110 /$ 75; vertical calibration, $100 \mu \mathrm{V}$ for SNA and unit recordings; horizontal calibration, 130 msec. B, Spike (trace 1 )- and random pulse (trace 2)-triggered averages of SNA. Sweeps, 1400; bin width, $1 \mathrm{msec}$; vertical calibration, $12 \mu \mathrm{V}$. C Post-R-wave averages of AP and SNA and histogram of RVL unit discharges. Sweeps, 1180; bin width, $1 \mathrm{msec}$ for the averages and $5 \mathrm{msec}$ for the histogram; vertical calibration for SNA, $40 \mu \mathrm{V}$.

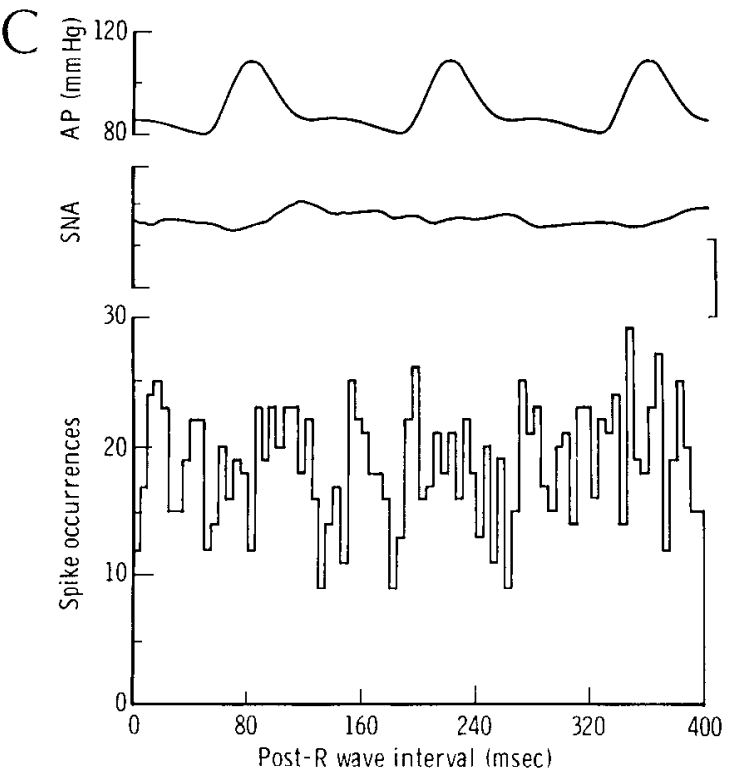

activity of RVL-spinal neurons is also influenced by inputs that are not locked to the cardiac cycle. In addition, temporal information in baroreceptor afferent activity may be diluted at synapses along the pathway leading to baroreceptor-mediated inhibition of RVL neurons.

Influence of the baroreceptor reflex. The clear relationship between the firing of RVL neurons and the cardiac cycle suggests that the neurons' activity is normally influenced by the discharge of baroreceptor afferents occurring during each systolic pressure rise. However, the peaks in the post-R-wave histograms of RVL unit discharge could have arisen either from excitation by the baroreceptors or from the release of baroreceptor inhibition during diastole (Morrison and Gebber, 1984). To assess the influence of maintained baroreceptor activation on the firing of RVL units, we recorded the activity of $44 \mathrm{RVL}-$ spinal neurons in response to elcvations in artcrial pressure produced by injections of a bolus of phenylephrine. As in the example in Figure $4 B$, pressor responses to phenylephrine completely inhibited (or greatly reduced) the discharge frequency of all RVL-spinal neurons and produced a simultaneous suppression of SNA. For the 33 RVL-spinal neurons that were silenced, the threshold mean arterial pressure for complete inhibition of their discharge averaged $137 \pm 5 \mathrm{mmHg}$ (range, 95-165 $\mathrm{mmHg}$ ).

We next examined the relationship between RVL-spinal unit activity and SNA after the removal of baroreceptor input by transection of the afferent nerves. As described by Gebber and Barman (1981), interruption of the baroreceptor input eliminates the possibility of obtaining a positive cross-correlation between the activity of a nonsympathetic neuron and SNA due solely to the influence of a shared baroreceptor input.

After denervation of all arterial baroreceptors, the spontaneous activity of RVL-spinal neurons and the rhythmic slow waves in the splanchnic SNA were maintained (Fig. 5A). The periodicity of the rhythmic bursts in SNA was reduced to 2-6 $\mathrm{Hz}$, an effect of baroreceptor denervation similar to that in cat (Gebber and Barman, 1981). Baroreceptor denervation abolished the link between the cardiac cycle and the slow waves in splanchnic nerve discharge. This is clearly indicated by the flat post-R-wave average of SNA (Fig. $5 C$, middle trace), in which the lack of any repeating pattern demonstrates that the slow waves in SNA occurred at random with respect to the R-wave trigger preceding each cardiac cycle. Section of baroreceptor afferents also abolished the cardiac-related component of RVL neuronal discharge (Fig. $5 C$, lower trace) and eliminated the inhibition of RVL unit activity and SNA previously elicited by the elevations in arterial pressure following systemic administration of phenylephrine.

Most striking, however, was the observation that in the ab- 


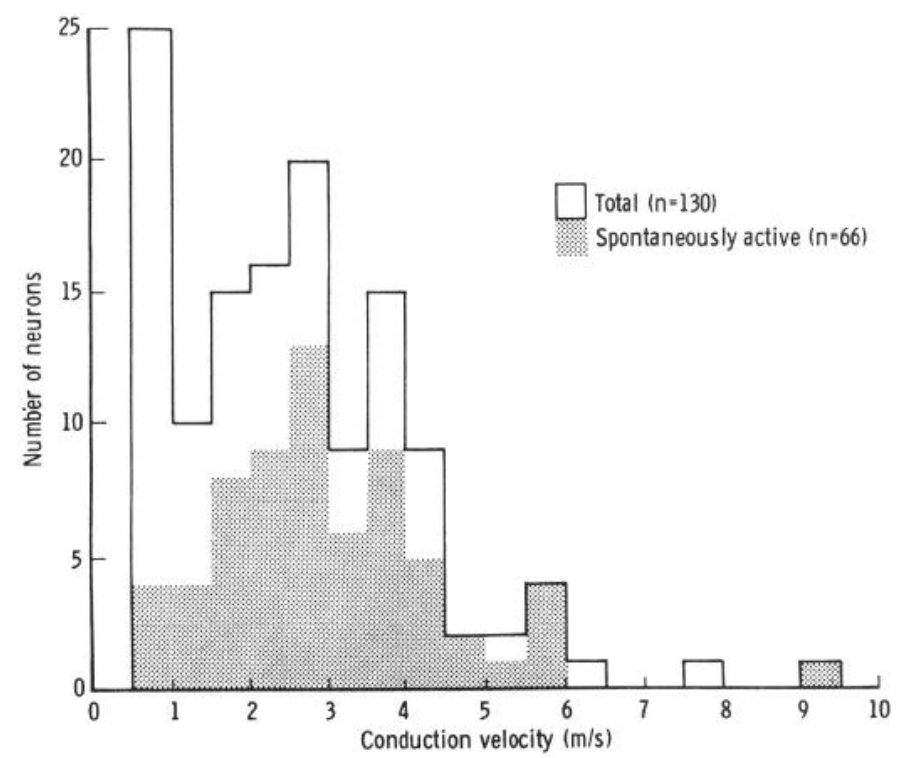

Figure 6. Histogram of the antidromic conduction velocities of the spinal axons of RVL neurons. Open bars represent total number of cells $(n=130)$, shading represents spontaneously active cells $(n=66)$. Note bimodal distribution suggesting myelinated and unmyelinated elements within the population.

sence of baroreceptor input, the temporal relationship between the spontaneous discharges of RVL-spinal neurons and the activity on the sympathetic nerve was preserved (Fig. $5 B$, trace 1). For 10 RVL-spinal neurons recorded following baroreceptor denervation, the mean lag between RVL-spinal unit spikes and peak activity in the succeeding bursts of SNA was $68 \pm 2 \mathrm{msec}$. This interval did not differ from the time between RVL unit discharge and peak SNA in rats with functional baroreceptor reflexes $(p>0.05)$. The correlation of RVL-spinal unit discharge with SNA following elimination of the potential coupling influences of baroreceptor afferent input indicates either that RVLspinal neurons comprise a reticulospinal pathway controlling spontaneous SNA or that they receive inputs from other medullary neurons that govern SNA.

\section{Conduction velocities of $R V L-$ spinal vasomotor neurons}

Antidromic conduction velocities of $R V L$-spinal neurons. The conduction velocities of the spinal axons of RVL neurons were calculated by dividing the distance between the recording and

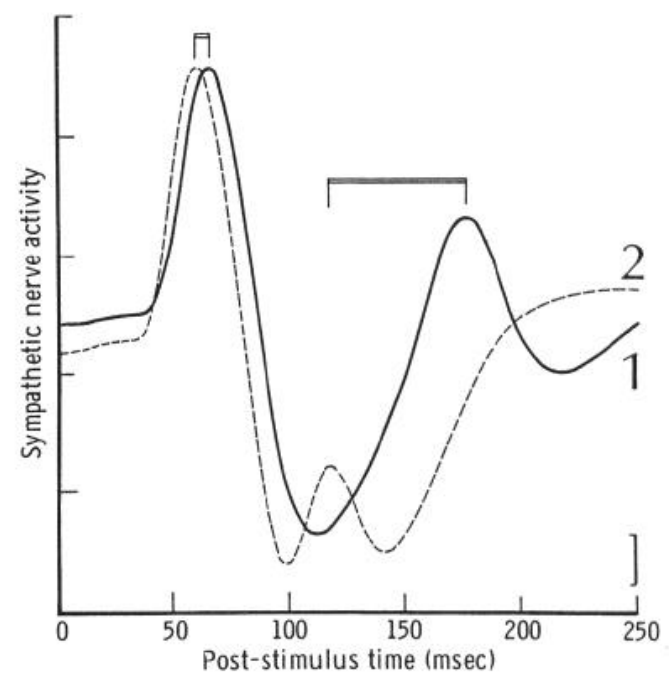

Figure 7. Averaged responses $(n=30)$ evoked in splanchnic sympathetic nerve by stimuli applied to RVL (trace $I$; stimuli: $50 \mu \mathrm{A}, 1 \mathrm{msec}$ duration, $0.5 \mathrm{~Hz}$ ) and to lateral funiculus of the thoracic spinal cord (trace 2; stimuli: $60 \mu \mathrm{A}, 1 \mathrm{msec}, 0.5 \mathrm{~Hz}$ ). Bin width, $1 \mathrm{msec}$; vertical calibration, $60 \mu \mathrm{V}$. Horizontal bars above traces indicate the conduction delays between corresponding peaks in the responses, used to calculate orthodromic conduction velocities (see text).

stimulating electrodes by the onset latency of the antidromic response elicited by electrical stimulation of the IML. In this study, RVL-spinal neurons were antidromically activated from the second thoracic segment, which was $32-35 \mathrm{~mm}$ from the $\mathrm{RVL}$ recording electrode. The antidromic onset latencies of the RVL neurons ranged from 3.9 to $64.0 \mathrm{msec}$. The distribution of the calculated axonal conduction velocities of $130 \mathrm{RVL}-$ spinal neurons is shown in Figure 6. For 25 neurons, the axonal conduction velocities were less than $1 \mathrm{~m} / \mathrm{sec}$, with a mean conduction velocity of $0.8 \pm 0.03 \mathrm{~m} / \mathrm{sec}$ (Table 1 ). Presumably, the axons of these neurons were unmyelinated (Lee et al., 1986). The mean axonal conduction velocity of the remaining $105 \mathrm{RVL}$ neurons was $3.1 \pm 0.1 \mathrm{~m} / \mathrm{sec}$, suggesting that this population consisted of lightly myelinated axons.

Comparison with orthodromic conduction velocities. Both the rapidly and the slowly conducting RVL-spinal neurons appear to be sympathoexcitatory, since (1) they were inhibited by activation of the baroreceptor reflex and (2) their activity was synchronized with the discharge of the sympathetic nerve. To

Table 1. Comparison of conduction velocities of RVL-spinal axons

\begin{tabular}{lll} 
Source & $\begin{array}{l}\text { Rapid (myelinated) } \\
(\mathrm{m} / \mathrm{sec})\end{array}$ & $\begin{array}{l}\text { Slow (unmyelinated) } \\
(\mathrm{m} / \mathrm{sec})\end{array}$ \\
\hline Antidromically activated RVL neurons & $3.1 \pm 0.1(n=105)$ & $0.8 \pm 0.03(n=25)$ \\
& $(1.1-9.2)$ & $(0.5-1.0)$ \\
Orthodromic activation of spinal & $2.8 \pm 0.2(n=20)$ & $0.6 \pm 0.02(n=12)$ \\
sympathoexcitatory pathways & $(1.4-4.6)$ & $(0.4-0.6)$ \\
PNMT-containing axons & $1.8-5.3(n=26)$ & $0.3-1.0(n=63)$
\end{tabular}

Three independent measurements of the conduction velocities of reticulospinal axons potentially involved in mediating sympathoexcitation of RVL origin are compared. The antidromic conduction velocities of RVL vasomotor neurons are the means \pm SEM and ranges of the data used to construct Figure 6 . The orthodromic conduction velocities of sympathoexcitatory pathways are the means \pm SEM and ranges of the measurements described in Figure 7 . The estimated conduction velocities for the spinal axons containing PNMT were obtained by multiplying their mean diameter by the range of scale factors relating axonal size to conduction velocity (see Discussion). 


Table 2. Splanclunic sympathetic nerve response latencies
\begin{tabular}{llll} 
Stimulus size & Onset $(\mathrm{msec})$ & Early peak $(\mathrm{msec})$ & Late peak $(\mathrm{msec})$ \\
\hline RVL & $41 \pm 1(n=28)$ & $71 \pm 1(n=28)$ & $166 \pm 3(n=21)$ \\
Spinal cord & $31 \pm 1(n=21)$ & $59 \pm 2(n=21)$ & $105 \pm 3(n=16)$
\end{tabular}

The temporal characteristics of the increases (Fig. 7) in splanchnic nerve activity evoked by single stimuli applied to vasomotor unit recording sites in the RVL or to the IML region of the second thoracic spinal segment. The separation of the stimulation sites in the medulla and the spinal cord averaged $34 \mathrm{~mm}$. In each rat, measurements were made from the averaged nerve response to 30 stimuli. Data are means \pm SEM.

provide further evidence that both the myelinated and the unmyelinated RVL-spinal pathways were sympathoexcitatory, we examined the effects of electrical stimulation of the RVL and of the upper thoracic spinal cord upon splanchnic SNA. This allowed us to compare the spinal conduction velocities of orthodromically evoked sympathetic excitatory potentials with the antidromic conduction velocities of RVL-spinal axons.

Stimuli (30-60 $\mu \mathrm{A}, 1 \mathrm{msec}, 0.5 \mathrm{~Hz}$ ) applied to sites in the RVL at which neurons had been antidromically activated from the IML elicited an excitatory evoked potential in the splanchnic nerve (Fig. 7, trace 1). The response was characterized by 2 peaks, with mean latencies to peak of 71 and $166 \mathrm{msec}$ (Table 2). Stimulation of the lateral funiculus of the second thoracic segment, i.e., the region containing the axons of RVL-spinal neurons (Ross et al., 1984a), also evoked an early and a late excitatory response in SNA (Fig. 7, trace 2). The latencies to the peaks of these responses were 59 and $105 \mathrm{msec}$ (Table 2).

Two observations suggest that spinal stimulation activated 2 descending sympathoexcitatory pathways with different conduction velocities. First, in 4 rats, both components of the sympathetic evoked response were maintained following cervical spinal cord transection at $\mathrm{C} 1-\mathrm{C} 2$, indicating that neither of the responses represented a reflex response integrated supraspinally. Second, the time between the early and the late peaks became shorter as the stimulating electrode was moved to more caudal thoracic segments. The 2 peaks eventually fused when stimulation was confined to the T6-T9 segments, which contain the preganglionic neurons of the splanchnic nerve (S. F. Morrison, personal observations). Thus, it is unlikely that the 2 peaks in the sympathetic response represent either repetitive excitation of spinal sympathetic neurons or activation of 2 pools of sympathetic preganglionic neurons with different conduction velocities.

While electrical stimulation of the $\mathrm{T} 2$ lateral funiculus may also have activated other descending inputs to the IML, the location of RVL-spinal axons in this position in the spinal cord (Ross et al., 1984a) suggests that activation of both the myelinated and unmyelinated axons of RVL-spinal neurons would contribute to the responses in the splanchnic nerve evoked from this site. Using this assumption, the spinal conduction velocity of each of the 2 sympathoexcitatory pathways activated by RVL stimulation was calculated by dividing the distance between the RVL and spinal stimulating electrodes by the time required for impulses to travel along each pathway from the RVL to the spinal stimulation site (Foreman and Wurster, 1973). For each pathway, the conduction time from the RVL to the spinal stimulation site is equal to the latency to the peak of the RVL evoked response minus the time from the spinal stimulation to the peak of the spinal evoked sympathetic response. Thus, the conduction time over the rapidly conducting pathway from the RVL to the upper thoracic stimulation site is represented by the left horizontal bracket in Figure 7, while that for the slowly conducting pathway is represented by the right horizontal bracket.

This analysis yields orthodromic conduction velocities in the RVL-spinal sympathoexcitatory pathways of $2.8 \mathrm{~m} / \mathrm{sec}$ and 0.6 $\mathrm{m} / \mathrm{sec}$ (Table 1). These findings providc an important demonstration that the sympathoexcitatory effects attributed to RVLspinal neurons are mediated over pathways with conduction velocities that are comparable to those of the RVL-spinal neurons. The slight discrepancies between the orthodromic and the antidromic results may have arisen from the skewed distribution of the antidromic conduction velocities of the cells sampled (Fig. 6).

Further evidence that antidromically identified RVL-spinal neurons mediate the sympathoexcitatory responses elicited from the RVL was obtained by comparing the latency to the peak of the SNA response following RVL stimulation and the delay between the spontaneous discharges of RVL-spinal neurons and the peak of the succeeding spontaneous burst in SNA. The mean latency to the early peak in the splanchnic SNA response to RVL stimulation was $71 \pm 1 \mathrm{msec}(n=28)$. This did not differ from the mean lag to peak SNA in the spike-triggered averages of RVL-spinal vasomotor neurons (67 $\pm 2 \mathrm{msec}$; $n=31)$.

\section{Location of $R V L-$ spinal vasomotor neurons}

Fast green dye spots iontophoretically deposited at the recording sites of 27 antidromically identified RVL-spinal vasomotor neurons were recovered in histological sections immunocytochemically labcled with an antibody to PNMT. As illustrated in Figure 8, the recording sites of these RVL-spinal neurons were consistently located within, or immediately adjacent to, the cluster of PNMT-containing neurons lying just caudal to the facial nerve nucleus and constituting the rostral pole of the $\mathrm{Cl}$ cell group. The distance from the center of the dye deposit to the nearest PNMT-labeled neuronal cell body in the same section was $69 \pm 5 \mu \mathrm{m}$. Included in this group were 4 RVL-spinal

Figure 8. Fast green dye deposit marking the recording sites of RVL-spinal vasomotor neurons. $A$, $C$, Low-magnification photomicrographs of coronal sections through the RVL region of different animals. Green dye deposits (arrows) are surrounded by cell bodies and processes containing the brown PAP reaction product, indicating PNMT immunoreactivity (Cl neurons). $B, D$, Higher magnification of $A$ and $C$, respectively, showing the proximity of the unit recording sites to $\mathrm{C} 1$ neurons. Calibration bars, $500 \mu \mathrm{m}(A) ; 25 \mu \mathrm{m}(B) ; 250 \mu \mathrm{m}(C) ; 50 \mu \mathrm{m}(D)$. 


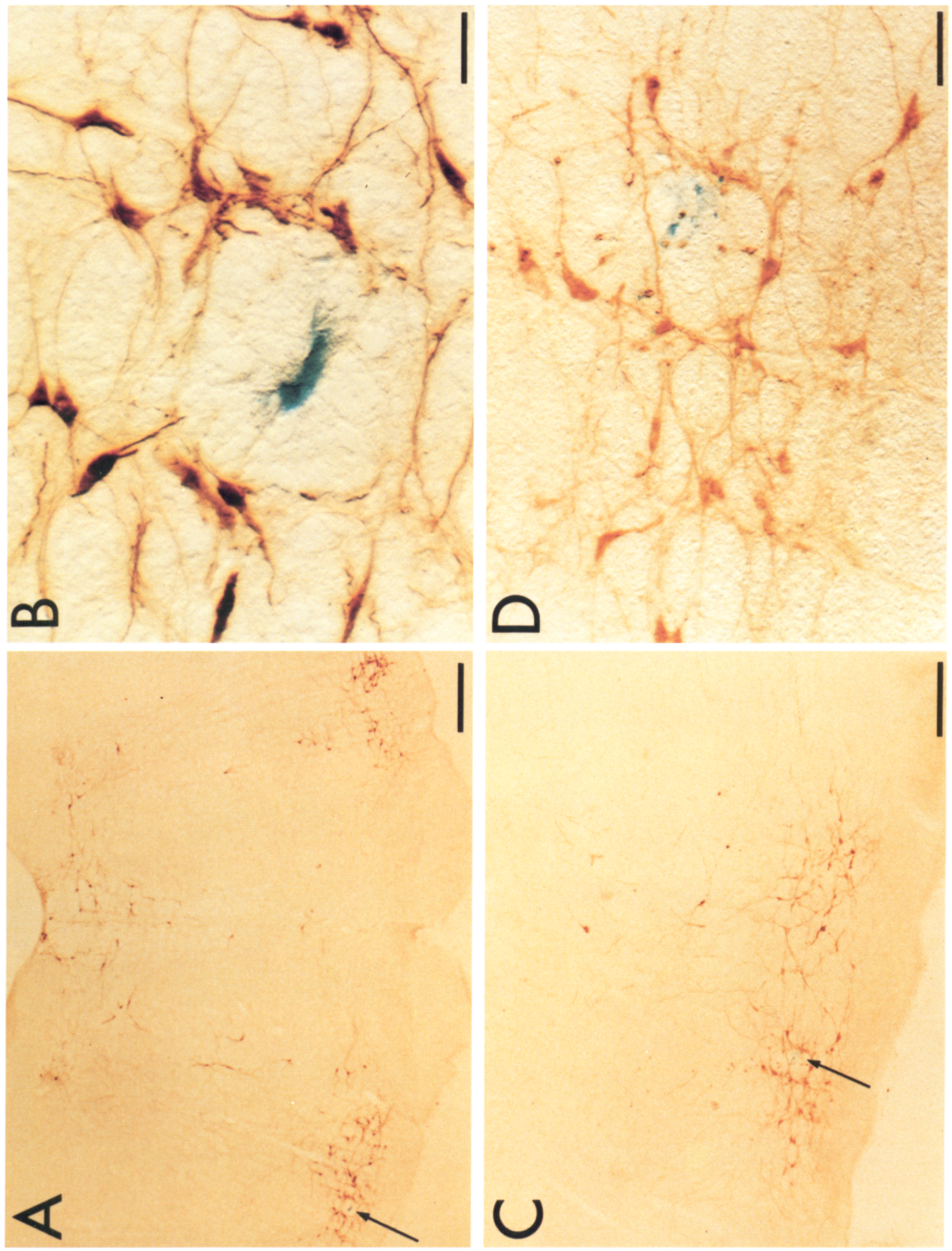



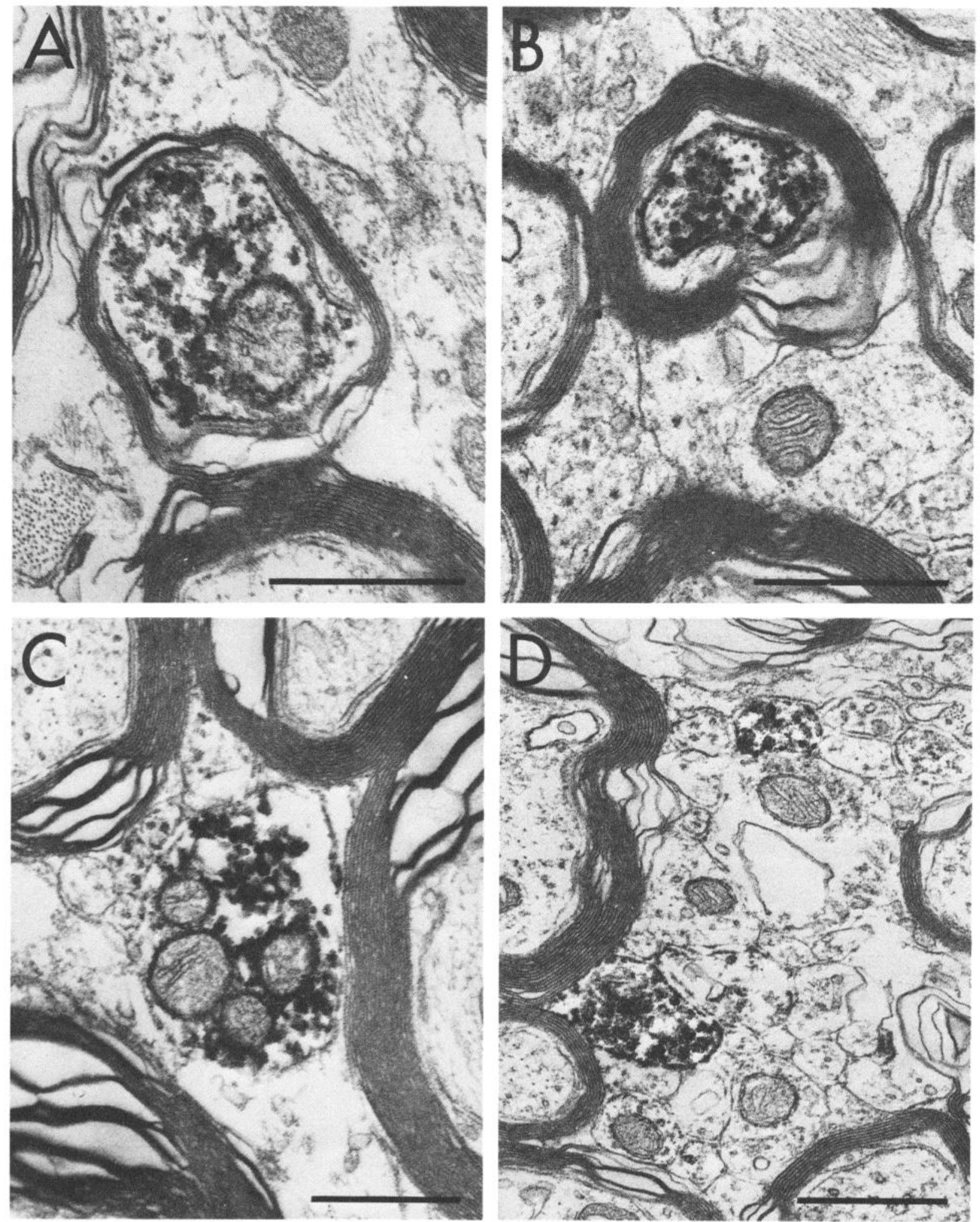

Figure 9. Electron micrographs showing the ultrastructural localization of PNMT in myelinated $(A, B)$ and unmyelinated $(C, D)$ axons in the lateral funiculus of the upper thoracic spinal cord. Calibration bar, $0.5 \mu \mathrm{m}$.

neurons with antidromic conduction velocities of less than 1 $\mathrm{m} / \mathrm{sec}$. Their mean distance to the nearest PNMT-containing soma was $79 \pm 8 \mu \mathrm{m}$, which was not different from that of RVL neurons with faster conduction velocities. In contrast, the re- cording sites of 5 spontaneously active neurons that were neither antidromically excited from the thoracic spinal cord nor inhibited by baroreceptor activation were located at a mean distance of $250 \pm 33 \mu \mathrm{m}$ from the nearest PNMT-labeled cell body. 
Ultrastructural analysis of spinal axons containing PNMT immunoreactivity

The finding that the $\mathrm{C} 1$ region of the RVL contains 2 populations of spinally projecting sympathoexcitatory neurons, one with myelinated and the other with unmyelinated axons, raises the question of whether both of these axonal classes arise from neurochemically similar cells. We therefore sought to determine whether the spinal cord contained PNMT-immunoreactive axons with diameters corresponding to the 2 ranges of conduction velocity determined for axons of RVL-spinal sympathoexcitatory neurons. Following immunocytochemical labeling for PNMT, coronal sections of the upper thoracic (T1-T3) spinal cord of 3 rats were prepared for electron-microscopic examination. Prior to embedding, these sections were trimmed to isolate the funicular region lateral to the border between the principal nucleus of the IMI and the spinal white matter. UItrastructural analysis revealed many axon profiles that contained PNMT immunoreactivity. These profiles ranged in size from $0.1-2.8 \mu \mathrm{m}$ in diameter, often contained mitochondria, and lacked synaptic contacts and vesicles. The latter characteristics allowed us to differentiate unmyelinated axonal profiles from those of dendrites or axon terminals.

Myelinated PNMT-containing axons (Fig. 9, $A, B$ ) were observed as individual profiles immediately surrounded by unlabeled axons lacking myelin. The myelin sheaths of PNMTlabeled axons had 5-20 laminae, with the majority having between 10 and 12 laminae. Unmyelinated axons containing PNMT (Fig. 9, $C, D$ ) were often seen in groups of 2 or 3 within bundles of unmyelinated axons.

The diamctcrs of labeled axon profiles were determined using an image analysis system to measure their areas (including myelin) from photomicrographs. The diameters of circles with equal areas were then calculated. The distributions of these diameters are shown in the histograms in Figure 10. The axonal diameters of myelinated PNMT-containing spinal axons ranged from 0.64 to $2.84 \mu \mathrm{m}$ (mean, $1.17 \pm 0.11 \mu \mathrm{m} ; n=26$ ). Unmyelinated spinal axuns containing PNMT had diameters (Fig. 10B) between 0.14 and $0.86 \mu \mathrm{m}$ (mean, $0.42 \pm 0.02 \mu \mathrm{m} ; n=63$ ).

To provide evidence that the unmyelinated fibers in the thoracic white matter were not simply terminal branches of myelinated C1-spinal axons, we also examined the lateral funiculus of the spinal cord at the midcervical (C3-C5) level for PNMT immunoreactivity. At this spinal level as well, both myelinated and unmyelinated fibers were found containing PNMT. The distribution of axonal diameters for these fibers was not different from those in the thoracic spinal cord.

\section{Discussion}

In the present investigation, we used electrophysiological methods to characterize the relationship between the discharges of reticulospinal "cardiovascular" neurons in the RVL and the activity in the splanchnic sympathetic nerve. In combination with immunocytochemical localization of PNMT, the functional identification of RVL neurons allowed us to determine whether the location of vasomotor neurons in the RVL corresponded to that of adrenergic neurons of the $\mathrm{Cl}$ group. We observed that the population of neurons in the RVL antidromically excited from the IML consisted of both rapidly and slowly conducting units, that both of these groups were sympathoexcitatory, and that their spontaneous discharges were inhibited by baroreceptor stimulation. The firing of RVL-spinal neurons
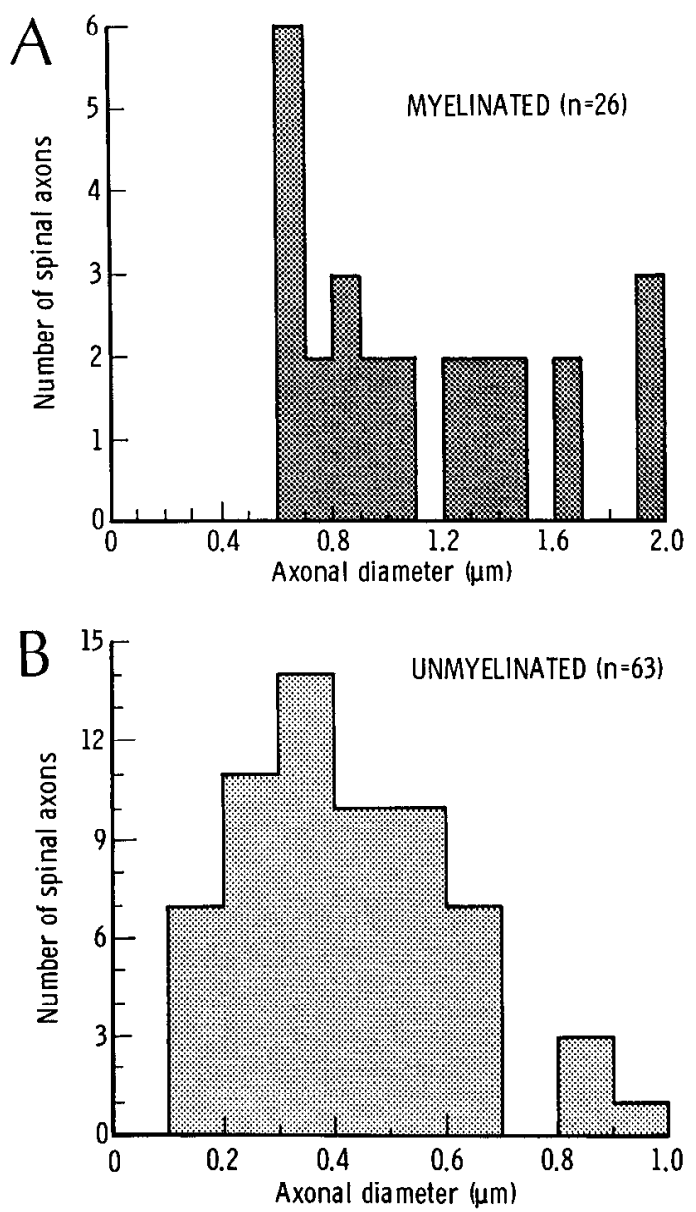

Figure 10. Histograms of the diameters of myelinated $(A ; n=26)$ and unmyelinated $(B ; n=63)$ spinal axons containing PNMT immunoreactivity. Data were obtained from electron micrographs.

was predictive of the discharge of sympathetic ncurons in the splanchnic nerve. Indeed, the cardiac rhythm in SNA appeared to be a consequence of the modulation of their spontaneous discharge by the rhythmic baroreceptor activation during each systole. The recording sites of RVL-spinal sympathoexcitatory neurons were surrounded by cell bodies containing PNMT. Moreover, in the lateral funiculus of the spinal cord, PNMT was contained within myelinated and unmyelinated axons. These results are entirely consistent with the view that the sympathoexcitatory neurons of the RVL are elements of the $\mathrm{C} 1$ group and that the spinally projecting neurons of the $\mathrm{Cl}$ group have myelinated and unmyelinated axons. Further, the data imply that groups of sympathoexcitatory neurons of the $\mathrm{Cl}$ area discharge simultaneously to produce a synchronous input to large pools of preganglionic neurons in the IML.

\section{Properties of $R V L-$ spinal neurons}

The RVL neurons antidromically activated from the IML can be divided into 2 groups on the basis of their conduction velocities. The first, comprising approximately $80 \%$ of the neurons, had axonal conduction velocities averaging $3.1 \mathrm{~m} / \mathrm{sec}$, suggesting that they were lightly myelinated. The remaining neurons had conduction velocities of less than $1 \mathrm{~m} / \mathrm{sec}$, implying that their axons were unmyelinated. The majority of the rapidly conducting neurons were spontaneously active, while, under the 
conditions of this study, most of those in the unmyelinated group were silent.

Several lines of evidence suggest that both myelinated and unmyelinated RVL-spinal neurons produce excitation of sympathetic preganglionic neurons.

First, electrical stimulation with single shocks in the $C 1$ area of the RVL elicited increases in SNA characterized by 2 peaks of excitation. The orthodromic conduction velocities of these 2 responses were comparable to the antidromic conduction velocities of the 2 populations of RVL-spinal neurons. Thus, it is unlikely that either of the excitatory responses elicited in the splanchnic nerve by RVL stimulation was due to activation of fibers passing through the region, or that RVL-spinal neurons were involved in descending sympathoinhibitory networks. Moreover, when the stimulating electrode was progressively moved from the brain stem into sites in the lateral funiculus of the spinal cord, not only was the latency to each peak reduced, but the difference between the 2 peaks was shortened. These observations suggest that the 2 excitatory peaks in the sympathetic response were produced by stimulation of 2 descending pathways with different conduction velocities rather than by activation of a single descending tract that elicited either repetitive firing of a pool of preganglionic neurons or excitation of 2 groups of preganglionic neurons containing axons of different conduction velocities.

Further support for the sympathoexcitatory role of RVLspinal neurons was obtained by analyzing the relationship between the discharge of individual RVL neurons and the bursts of excitation in splanchnic nerve fibers. Spike-triggered averaging demonstrated that the spontaneous action potentials of both rapidly and slowly conducting RVL neurons were temporally related to the peak of excitation in the subsequent bursts of SNA. With the baroreceptor reflexes intact, the discharges of RVL neurons were synchronized with the cardiac rhythm in the splanchnic nerve. Significantly, elimination of the baroreceptor input did not alter the locking of RVL unit activity to the SNA, even though the sympathetic slow waves now exhibited a freerunning rhythm that was no longer related to the cardiac cycle. These data provide strong support for a causal relationship between the spontaneous discharges of RVL-spinal neurons and the bursts of excitation in sympathetic nerves.

Finally, the sympathoexcitatory nature of the RVL-spinal projection neurons was suggested by the finding that the discharges of neurons in both the rapidly and slowly conducting populations were inhibited in parallel with SNA during baroreceptor stimulation elicited by increases in arterial pressure. Thus, baroreceptor-mediated sympathoinhibition arises, at least in part, from the disfacilitation of sympathetic preganglionic neurons resulting from inhibition of RVL-spinal neurons by input from the baroreceptors, presumably conveyed over pathways from the NTS. In this regard, the synchrony of the sympathetic slow waves with the cardiac cycle in baroreceptor-intact animals appears to be a consequence of the rhythmic wave of inhibition of RVL-spinal neurons following activation of the baroreceptor reflex during each systolic pressure rise (Barman and Gebber, 1983; Brown and Guyenet, 1984). While stimulation of the baroreceptors has been shown to produce sympathoinhibition at a spinal locus (Coote and Macleod, 1974; Taylor and Gebber, 1975), the functional implications of this mechanism remain to be determined.

The reticulospinal neurons described here share, to a large extent, characteristics with neurons recorded in a similar medullary region of the cat (Barman and Gebber, 1983, 1985;
McAllen, 1986), rat (Brown and Guyenet, 1984, 1985), and rabbit (Terui et al., 1986). Thus, in all 3 species, ventromedullary neurons can be antidromically activated from sites in the thoracic spinal cord. Our results are in agreement with the extensive antidromic mapping study of the cat spinal cord (Barman and Gebber, 1985) that demonstrated that the IML was the most likely termination site of these ventrolateral medullary neurons, indicating that they are primarily involved in the control of sympathetic preganglionic neurons. A significant percentage of spontaneously active neurons and an inhibitory influence of the baroreceptor reflex on their discharge were also common findings. Only in the cat (Barman and Gebber, 1983) was the temporal relationship between the firing of ventrolateral medullary neurons and SNA examined with and without baroreceptor influences. Similar to the results reported here in the rat, the finding of a maintained correlation in the cat between unit activity and SNA following baroreceptor denervation is consistent with the involvement of ventrolateral medullary neurons in sympathetic generating networks. That the RVL-spinal pathway consists of both myelinated and unmyelinated axons appears to be characteristic of the rat (Brown and Guyenet, 1985) and the rabbit (Terui et al., 1986), but, interestingly, not of the cat (Barman and Gebber, 1985).

\section{Relationship of RVL-spinal neurons to CI neurons}

The present study provides 2 lines of evidence to support the view that PNMT-containing neurons of the $\mathrm{C} 1$ group contribute to both the myelinated and unmyelinated components of the RVL-spinal pathway.

The first derives from the observation that in every instance in which the position of the tip of the RVL recording electrode was localized in sections immunocytochemically labeled for PNMT, the recording sites were within approximately $70 \mu \mathrm{m}$ of a PNMT-containing cell body. Given the rich dendritic arborization and fairly large size of $\mathrm{Cl}$ neurons (Ruggiero et al., 1985 ), it is probable that at least a few elements of the $\mathrm{Cl}$ group were within the recording distance (about $100 \mu \mathrm{m}$ ) of the electrodes used in these experiments. Indeed, our technique may have overestimated the distance between the electrode tip and the nearest PNMT-containing neuron. Since the dye spot was often surrounded by $\mathrm{C} 1$ neurons, the passage of current to deposit the dye may have destroyed a PNMT-containing cell located at the electrode tip. Also, a $\mathrm{Cl}$ neuron lying just rostral or caudal to the recording site may have been lost in the sectioning procedure. Whether PNMT is contained within the reticulospinal neurons with the electrophysiological characteristics described by ourselves and others will only be proven by combining intracellular marking with immunocytochemistry. Thus, while it is possible that another class of reticulospinal vasomotor neurons may be admixed with $\mathrm{Cl}$ neurons, our demonstration that RVL vasomotor neurons lie within or immediately adjacent to the $\mathrm{Cl}$ cell group indicates that the cytochemical designation of the $\mathrm{Cl}$ area, rather than the anatomically defined PGCL nucleus, provides a more specific localization of the neurons comprising the RVL-spinal projection. That $\mathrm{Cl}$ neurons project directly and exclusively to the IML, surrounding the sympathetic preganglionic neurons in a rich plexus of PNMTcontaining terminals (Ross et al., 1984a), is consistent with this conclusion.

The second line of evidence comes from our localization of PNMT-containing axons in the area of the lateral funiculus, through which the axons of RVL-spinal neurons descend (Ross et al., 1984a). Here, PNMT immunoreactivity was found in 
both myelinated and unmyelinated axons. The possibility that these PNMT-containing axons were elements of the rapidly and slowly conducting RVL-spinal sympathoexcitatory pathways was examined by estimating the conduction velocities of the PNMT-containing axons using scale factors relating axonal diameter $(\mu \mathrm{m})$ and conduction velocity $(\mathrm{m} / \mathrm{sec})$.

This relationship was originally described as a linear one in which velocity was 6 times the diameter (Hursh, 1939). More recent studies have indicated nonlinearities in the case of smaller-diameter myelinated fibers, resulting in scale factors between 1.5 and $4.5 \mathrm{~m} / \mathrm{sec} / \mu \mathrm{m}$ for axons with diameters from 2 to 10 $\mu \mathrm{m}$ (Bessou and Perl, 1966; Boyd and Kalu, 1979; Lee et al., 1986). Application of this range of scale factors to estimate the conduction velocities of the myelinated PNMT-containing spinal axons (Table 1) provides only an approximate comparison since the axons used to determine these scale factors were (1) from various peripheral sensory nerves of the cat and (2) larger than the myelinated PNMT-containing axons described here. In relating axonal size to conduction velocity for unmyelinated fibers, Lee et al. (1986) found that the central processes of C cells in dorsal root ganglia with diameters of $0.2-1.0 \mu \mathrm{m}$ had conduction velocities of $0.3-1.0 \mathrm{~m} / \mathrm{sec}$. On the basis of these results, the unmyelinated PNMT-immunoreactive fibers in the spinal cord would also be expected to conduct impulses between 0.3 and $1.0 \mathrm{~m} / \mathrm{sec}$. As shown in Table 1, the calculated conduction velocities of both groups of PNMT-containing axons are in agreement with those determined antidromically for RVL neurons projecting to the IML. Thus, the anatomic substrate exists to suggest that the sympathoexcitatory effects of RVLspinal vasomotor neurons are mediated, at least in part, over axons containing PNMT.

\section{C1 neurons as cardiovascular neuroregulatory units in the} $R V L$

The evidence supporting the view that neurons of the $\mathrm{C} 1$ group are the critical elements within the RVL in governing the circulation is based on studies in which the distribution of $\mathrm{Cl}$ neurons, defined by immunocytochemical labeling for PNMT, has been combined with the tracing of efferent pathways (Ross et al., 1981, 1984a), with analysis of functional changes in arterial pressure associated with electrical or chemical stimulation (Ross et al., 1983, 1984b), or with local impairment of neuronal function produced by drugs or lesions (Ross et al., 1983; Granata et al., 1985; Benarroch et al., 1986b). Such studies have demonstrated that neurons within a restricted region ( $\mathrm{Cl}$ area) of the RVL corresponding to the rostral pole of the $\mathrm{Cl}$ cell group directly innervate the IML, correspond to sites of the lowest threshold at which electrical or chemical stimulation elevates arterial pressure, and comprise the precise location wherein lesions result in collapse of arterial pressure and abolition of baroreceptor and other cardiovascular reflexes. On this basis we have proposed (Ross et al., 1983, 1984b) that $\mathrm{Cl}$ adrenergic neurons are tonically active, that they provide a critical sympathoexcitatory drive to the IML, maintaining sympathetic tone, and that changes in the firing of these neurons underlie baroreceptormediated sympathoinhibition as well as many sympathoexcitatory responses.

The results of the present study support this concept. The electrophysiological characteristics of spinal projection neurons in the $\mathrm{Cl}$ area-possibly $\mathrm{Cl}$ neurons themselves-are entirely consistent with our interpretation of their role in the tonic and reflex control of the circulation. The fact that a majority of RVLspinal neurons are spontaneously active and subserve a sym- pathoexcitatory function is appropriate for a role in governing resting levels of SNA and, hence, arterial pressure. That these neurons are inhibited by baroreceptor stimulation is in agreement with evidence that $\mathrm{Cl}$ arca ncurons are essential for expression of the vasomotor component of the baroreceptor reflex and suggests that baroreceptor input leads to reductions in arterial pressure through inhibition of RVL-spinal neuronal activity.

The finding that the discharges of any RVL-spinal unit was correlated with the bursts of splanchnic SNA is not only consistent with a potent influence of $\mathrm{Cl}$ area neurons on the excitability of spinal sympathetic neurons, but also suggests that a significant number of RVL-spinal neurons discharge synchronously. As described in the cat (Barman et al., 1982), the simultaneous discharge of $\mathrm{Cl}$ area neurons could arise from a common input shared by these neurons or from local interconnecting networks, a possibility supported by the anatomical observation that PNMT-containing neurons of the $\mathrm{Cl}$ area are innervated by PNMT-containing axon terminals (Milner et al., 1987). Moreover, the finding that the discharge of individual RVL-spinal neurons was locked to multifiber bursts of action potentials in the splanchnic nerve implies that the axons of these neurons collateralize to innervate pools of spinal sympathetic neurons. While this interpretation is supported by a study of axonal branching of cat RVL-spinal neurons (Barman and Gebber, 1985), branching of spinal interneurons may also contribute to this relationship. Thus, the potency and widespread influence of the spinally projecting vasomotor neurons of the $\mathrm{Cl}$ area would explain the reduction of arterial pressure to spinal levels that follows bilateral lesion of this reticular region (Ross et al., 1983; Granata et al., 1985).

It should be cautioned that while the evidence strongly supports the involvement of $\mathrm{Cl}$ neurons in governing sympathetic activity and arterial pressure, the identity of the transmitter released from RVL-spinal neurons is not certain. Although it can be assumed that $\mathrm{C} 1$ neurons synthesize and release epinephrine, there is no evidence that epinephrine itself is the spinal sympathoexcitatory transmitter. Epinephrine can be detected in the rat spinal cord (Reid et al., 1975) and catecholamine terminals synapse directly on sympathetic preganglionic neurons (Chiba and Masuko, 1986; Milner et al., 1988). However, iontophoretically applied catecholamines, including epinephrine, inhibit the spontaneous firing of sympathetic preganglionic neurons (Coote ct al., 1981; Guyenet and Cabot, 1981). In contrast, intracellular recordings from preganglionic neurons in vitro indicate that both norepinephrine and epinephrine increase the excitability of preganglionic neurons through alterations in their postspike potentials (Yoshimura et al., 1987). The issue of whether spinal epinephrine is sympathoexcitatory or inhibitory, the possible role of spinal interneurons in sympathetic pathways (Barman and Gebber, 1984), and the potential for corelease of amines with other transmitters in the IML (Appel et al., 1986) leave open the identity of the RVL-spinal neurotransmitter. Nevertheless, the evidence strongly favors the cytological identification of the rostral $\mathrm{Cl}$ area as a site of tonic vasomotor neurons in the brain stem.

\section{References}

Amendt, K., J. Czachurski, K. Dembowsky, and H. Seller (1979) Bulbospinal projections to the intermediolateral cell column; a neuroanatomical study. J. Auton. Nerv. Syst. 1: 103-117.

Andrew, B. L. (1954) A laryngeal pathway for aortic baroreceptor impulses. J. Physiol. (Lond.) 125: 352-360.

Appel, N. M., M. W. Wessendorf, and R. P. Elde (1986) Coexistence of serotonin- and substance P-like immunoreactivity in nerve fibers 
apposing identified sympathoadrenal preganglionic neurons in rat intermediolateral cell column. Neurosci. Lett. 65: 241-246.

Armstrong, D. M., C. A. Ross, T. H. Joh, V. M. Pickel, and D. J. Reis (1982) Distribution of dopamine-, noradrenaline-, and adrenalinecontaining cell bodies in rat medulla oblongata: Demonstrated by the immunocytochemical localization of catecholamine biosynthetic enzymes. J. Comp. Neurol. 212: 173-187.

Baljet, B., and J. Drukker (1979) The extrinsic innervation of the abdominal organs in the female rat. Acta Anat. 104: 243-267.

Barman, S. M., and G. L. Gebber (1983) Sequence of activation of ventrolateral and dorsal medullary sympathetic neurons. Am. J. Physiol. 245: R438-R447.

Barman, S. M., and G. L. Gebber (1984) Spinal interneurons with sympathetic nerve-related activity. Am. J. Physiol. 247: R761-R767.

Barman, S. M., and G. L. Gebber (1985) Axonal projection patterns of ventrolateral medullospinal sympathoexcitatory neurons. J. Neurophysiol. 53: 1551-1566.

Barman, S. M., S. F. Morrison, and G. L. Gebber (1982) Short time scale interactions between brainstem neurons with sympathetic nerverelated activity. Brain Res. 250: 173-177.

Benarroch, E. E., A. R. Granata, D. A. Ruggiero, D. H. Park, and D. J. Reis (1986a) Neurons of $\mathrm{Cl}$ area mediate cardiovascular responses initiated from ventral medullary surface. Am. J. Physiol. 250: R932-R945.

Benarroch, E. E., A. R. Granata, R. Giuliano, and D. J. Reis (1986b) Neurons of the $\mathrm{Cl}$ area of rostral ventrolateral medulla mediate nucleus tractus solitarii hypertension. Hypertension 8 (Suppl. I): 156160.

Bessou, P., and E. R. Perl (1966) A movement receptor of the small intestine. J. Physiol. (Lond.) 182: 404-426.

Boyd, I. A., and K. U. Kalu (1979) Scaling factor relating conduction velocity and diameter for myelinated afferent nerve fibers in the cat hind limb. J. Physiol. (Lond.) 289: 277-297.

Brown, D. L., and P. G. Guyenet (1984) Cardiovascular neurons of brain stem with projections to spinal cord. Am. J. Physiol. 247: R1009R1016.

Brown, D. L., and P. G. Guyenet (1985) Electrophysiological study of cardiovascular neurons in the rostral ventrolateral medulla in rats. Circ. Res. 56: 359-369.

Celler, B. G., and L. P. Schramm (1981) Pre- and postganglionic sympathetic activity in splanchnic nerves of rats. Am. J. Physiol. 241: R55-R61.

Chiba, T., and S. Masuko (1986) Direct synaptic contacts of catecholamine axons on the preganglionic sympathetic neurons in the rat thoracic spinal cord. Brain Res. 380: 405-408.

Coote, J. H., and V. H. Macleod (1974) Evidence for the involvement in the baroreceptor reflex of a descending inhibitory pathway. J. Physiol. (Lond.) 241: 477-496.

Coote, J. H., V. H. Macleod, S. Fleetwood-Walker, and M. P. Gilbey (1981) The response of individual sympathetic preganglionic neurones to microiotophoretically applied endogenous monoamines. Brain Res. 215: 135-145.

Dampney, R. A. L., and E. A. Moon (1980) Role of ventrolateral medulla in vasomotor response to cerebral ischemia. Am. J. Physiol. 239: H349-H358.

Foreman, R. D., and R. D. Wurster (1973) Localization and functional characteristics of descending sympathetic spinal pathways. Am. J. Physiol. 225: 212-217.

Gebber, G. L., and S. M. Barman (1981) Sympathetic-related activity of brain stem neurons in baroreceptor-denervated cats. Am. J. Physiol. 240: R348-R355.

Gootman, P. M., M. I. Cohen, M. P. Piercey, and P. Wolotsky (1975) A search for medullary neurons with activity patterns similar to those in sympathetic nerves. Brain Res. 87: 395-406.

Granata, A. R., D. A. Ruggerio, D. H. Park, T. H. Joh, and D. J. Reis (1985) Brainstem area with $\mathrm{Cl}$ epinepherine neurons mediates baroreflex vasodepressor responses. Am. J. Physiol. 248: H547-H567.

Guertzenstein, P. G., and A. Silver (1974) Fall in blood pressure produced from discrete regions of the ventral surface of the medulla by glycine and lesions. J. Physiol. (Lond.) 242: 489-503.

Guyenet, P. G., and J. B. Cabot (1981) Inhibition of sympathetic preganglionic neurons by catecholamines and clonidine: Mediation by an alpha-adrenergic receptor. J. Neurosci. 1: 908-917.

Helke, C. J., J. J. Neil, V. J. Massari, and A. D. Loewy (1982) Substance $P$ neurons project from the ventral medulla to the intermediolateral cell column and ventral horn in the rat. Brain Res. 243: 147-152.
Hilton, S. M., J. M. Marshall, and R. J. Timms (1983) Ventral medullary relay neurones in the pathway from the defence areas of the cat and their effect on blood pressure. J. Physiol. (Lond.) 345: 149166

Hofer, M. A. (1985) Nutrient control of cardiac rate in newborn rats: Role of arterial baroreceptors. Am. J. Physiol. 249: R443-R448.

Hökfelt, T., K. Fuxe, M. Goldstein, and O. Johansson (1974) Immunohistochemical evidence for the existence of adrenaline neurons in the rat brain. Brain Res. 66: 235-251.

Hursh, J. B. (1939) Conduction velocity and diameter of nerve fibers. Am. J. Physiol. 127: 131-139.

Joh, T. H., and M. Goldstein (1973) Isolation and characterization of multiple forms of phenylethanolamine $N$-methyltransferase. Mol. Pharmacol. 9: 117-129.

Joh, T. H., and M. E. Ross (1983) Preparation of catecholamine synthesizing enzymes as immunogen for immunocytochemistry. In $\mathrm{Im}$ munocytochemistry, IBRO Handbook Series, A. C. Cuello, ed., pp. 121-138, Wiley, Chichester, UK

Koizumi, K., H. Seller, A. Kaufman, and C. M. Brooks (1971) Pattern of sympathetic discharges and their relation to baroreceptor and respiratory activities. Brain Res. 27: 281-294.

Lee, K. H., K. Chung, J. M. Chung, and R. E. Coggeshall (1986) Correlation of cell body size, axon size, and signal conduction velocity for individually labelled dorsal rool ganglion cells in the cat. J. Comp. Neurol. 243: 335-346.

Lipski, J. (1981) Antidromic activation of neurons as an analytic tool in the study of the central nervous system. J. Neurosci. Methods 4 $1-32$.

Loewy, A. D., and H. Burton (1978) Nuclei of the solitary tract: Efferent projections to the lower brainstem and spinal cord of the cat. J. Comp. Neurol. 181: 421-450.

Loewy, A. D., and S. McKellar (1981) Serotonergic projections from the ventral medulla to the intermediolateral cell column in the rat. Brain Res. 211: 146-152.

McAllen, R. M. (1985) Mediation of the fastigial pressor response and a somatosympathetic reflex by ventral medullary neurones in the cat. J. Physiol. (Lond.) 368: 423-433.

McAllen, R. M. (1986) Identification and properties of sub-retrofacia bulbospinal neurones: A descending cardiovascular pathway in the cat. J. Auton. Nerv. Syst. 17: 151-164.

McAllen, K. M., J. J. Neil, and A. D. Loewy (1982) Effects of kainic acid applied to the ventral surface of the medulla oblongata on vasomotor tone, the baroreceptor reflex and hypothalamic autonomic responses. Brain Res. 238: 65-76.

McDonald, D. M. (1983) Morphology of the rat carotid sinus nerve. I. Course, connections, dimensions and ultrastructure. J. Neurocytol 12: $345-372$

Milner, T. A., V. M. Pickel, D. H. Park, T. H. Joh, and D. J. Reis (1987) Phenylethanolamine $N$-methyltransferase-containing neurons in the rostral ventrolateral medulla of the rat: I. Normal ultrastructure. Brain Res. 411:28-45.

Milner, T. A., S. F. Morrison, C. Abate, and D. J. Reis (1988) Phenylethanolamine $N$-methyltransferase-containing terminals synapse directly on sympathetic preganglionic neurons in the rat. Brain Res. (in press).

Morrison, S. F., and G. L. Gebber (1985) Axonal branching patterns and funicular trajectories of raphe spinal sympathoinhibitory neurons. J. Neurophysiol. 53: 759-772.

Morrison, S. F., T. A. Milner, V. M. Pickel, and D. J. Reis (1986) Reticulospinal sympathoexcitatory neurons in the $\mathrm{Cl}$ region of the rostral ventrolateral medulla (RVL) may mediate the supraspinal component of the somatosympathetic reflex. Soc. Neurosci. Abstr. 12: 1157

Muira, M., T. Onai, and K. Tarayama (1983) Projections of upper structure to spinal cardioacceleratory center in cats: An HRP study using a new microinjection method. J. Auton. Nerv. Syst. 7: 119139.

Pickel, V. M. (1981) Immunocytochemical methods. In Neuroanatomical Tract Tracing Methods, L. Heimer and M. J. Robards, eds., pp. 483-509, Plenum, New York.

Reid, J. L., J. A. Zivin, F. Foppen, and I. J. Kopin (1975) Catecholamine neurotransmitters and synthetic enzymes in the rat spinal cord. Life Sci. 16: 975-984.

Reynolds, E.S. (1963) The use of lead citrate at high pH as an electronopaque stain for electron microscopy. J. Cell Biol. 17: 208.

Ross, C. A., D. M. Armstrong, D. A. Ruggiero, V. M. Pickel, T. H. 
Joh, and D. J. Reis (1981) Adrenaline neurons in the rostral ventrolateral medulla innervate thoracic spinal cord: A combined immunocytochemical and retrograde transport demonstration. Neurosci. Lett. 25: 257-262.

Ross, C. A., D. A. Ruggiero, T. II. Joh, D. II. Park, and D. J. Reis (1983) Adrenaline synthesizing neurons in the rostral ventrolateral medulla: A possible role in tonic vasomotor control. Brain Res. 273: 356-361.

Ross, C. A., D. A. Ruggiero, T. H. Joh, D. H. Park, and D. J. Reis (1984a) Rostral ventrolateral medulla: Selective projections to the thoracic autonomic cell column from the region containing $\mathrm{Cl}$ adrenaline neurons. J. Comp. Neurol. 228: 168-185.

Ross, C. A., D. A. Ruggiero, D. H. Park, T. H. Joh, A. F. Sved, J. Fernandez-Pardal, J. M. Saavedra, and D. J. Reis (1984b) Tonic vasomotor control by the rostral ventrolateral medulla: Effect of electrical or chemical stimulation of the area containing $\mathrm{Cl}$ adrenaline neurons on arterial pressure, heart rate, and plasma catecholamines and vasopressin. J. Neurosci. 4: 474-494.

Ross, C. A., D. A. Ruggiero, and D. J. Reis (1985) Projections from the nucleus tractus solitarii to the rostral ventrolateral medulla. J. Comp. Neurol. 242: 511-534.

Ruggiero, D. A., C. A. Ross, M. Anwar, D. H. Park, T. H. Joh, and D $J$. Reis (1985) Distribution of neurons containing phenylethanol amine $N$-methyltransferase in medulla and hypothalamus of rat. $\mathrm{J}$. Comp. Neurol. 239: 127-154.

Sapru, H. N., E. R. Gonzalez, and A. J. Krieger (1982) Greater splanchnic nerve activity in the rat. Brain Res. Bull. 8: 267-272.
Schachner, M., E. T. Hedley-Whyte, D. W. Hse, G. Schoonmaker, and A. Begnami (1977) Ultrastructure of glial fibrillary acidic protein in mouse cerebellum by immunoperoxidase labeling. J. Cell Biol. 75: 67-73.

Sternberger, L. A. (1979) Immunocytochemistry, Wiley, New York.

Sun, M. K., and P. G. Guyenet (1985) GABA-mediated baroreceptor inhibition of reticulospinal neurons. Am. J. Physiol. 249: R672-R680.

Swadlow, H. A. (1982) Antidromic activation: Measuring the refractory period at the site of axonal stimulation. Exp. Neurol. 75: 514519.

Taylor, D. G., and G. L. Gebber (1975) Baroreceptor mechanisms controlling sympathetic nervous rhythms of central origin. Am. J. Physiol. 228: 1002-1013.

Terui, N., Y. Saeki, and M. Kumada (1986) Barosensory neurons in the ventrolateral medulla in rabbits and their responses to various afferent inputs from peripheral and central sources. Jpn. J. Physiol. 36: $1141-1164$.

Willette, R. N., A. J. Kreiger, P. P. Barcas, and H. N. Sapru (1983) Mcdullary gamma-aminobutryic acid (GABA) receptors and the regulation of blood pressure in the rat. J. Pharmacol. Exp. Ther. 226: 893-899.

Willette, R. N., S. Punnen, A. J. Krieger, and H. N. Sapru (1984) Interdependence of rostral and caudal ventrolateral medullary areas in the control of blood pressure. Brain Res. 321: 169-174.

Yoshimura, M., C. Polosa, and S. Nishi (1987) Noradrenaline-induced afterdepolarization in cat sympathetic preganglionic neurons in vitro. J. Neurophysiol. 57: 1314-1324. 